\title{
Future projection of Indian summer monsoon variability under climate change scenario: An assessment from CMIP5 climate models
}

\author{
S. Sharmila, S. Joseph, A. K. Sahai*, S. Abhilash and R. Chattopadhyay \\ Indian Institute of Tropical Meteorology \\ Short Title: Future projections of ISM from CMIP5 models \\ Revised manuscript submitted to Global and Planetary Change
}

*Corresponding author

Dr. A. K. Sahai

Indian Institute of Tropical Meteorology

Dr. Homi Bhabha Road, Pashan, Pune-411008, INDIA

Email: sahai@tropmet.res.in

S. Sharmila: sharmila@tropmet.res.in

S. Joseph: susmitha@tropmet.res.in

S. Abhilash: abhi@tropmet.res.in

R. Chattopadhyay: rajib@tropmet.res.in 


\section{Abstract}

In this study, the impact of enhanced anthropogenic greenhouse gas emissions on the possible future changes in different aspects of daily-to-interannual variability of Indian summer monsoon (ISM) is systematically assessed using 20 coupled models participated in the Coupled Model Inter-comparison Project Phase 5. The historical (1951-1999) and future (2051-2099) simulations under the strongest Representative Concentration Pathway have been analyzed for this purpose. A few reliable models are selected based on their competence in simulating the basic features of present-climate ISM variability. The robust and consistent projections across the selected models suggest substantial changes in the ISM variability by the end of $21^{\text {st }}$ century indicating strong sensitivity of ISM to global warming. On the seasonal scale, the all-India summer monsoon mean rainfall is likely to increase moderately in future, primarily governed by enhanced thermodynamic conditions due to atmospheric warming, but slightly offset by weakened large scale monsoon circulation. It is projected that the rainfall magnitude will increase over core monsoon zone in future climate, along with lengthening of the season due to late withdrawal. On interannual timescales, it is speculated that severity and frequency of both strong monsoon (SM) and weak monsoon (WM) might increase noticeably in future climate. Substantial changes in the daily variability of ISM are also projected, which are largely associated with the increase in heavy rainfall events and decrease in both low rain-rate and number of wet days during future monsoon. On the subseasonal scale, the model projections depict considerable amplification of higher frequency (below 30day mode) components; although the dominant northward propagating 30-70 day mode of monsoon intraseasonal oscillations may not change appreciably in a warmer climate. It is speculated that the enhanced high frequency mode of monsoon ISOs due to increased GHG induced warming may notably modulate the ISM rainfall in future climate. Both extreme wet and dry episodes are likely to 
intensify and regionally extend in future climate with enhanced propensity of short active and long break spells. The SM (WM) could also be more wet (dry) in future due to the increment in longer active (break) spells. However, future changes in the spatial pattern during active/break phase of SM and WM are geographically inconsistent among the models. The results point out the growing climate-related vulnerability over Indian subcontinent, and further suggest the requisite of profound adaptation measures and better policy making in future.

Keywords: monsoon variability, climate change, future projection, CMIP5 


\section{Introduction}

The global warming due to the gradual increase in the anthropogenic greenhouse gas (GHG) emissions is unequivocal (IPCC 2007). Multi-model projections of future global monsoon indicate significant increase in the monsoon area and precipitation in GHG-induced warmer climate (Lee and Wang, 2014; Kitoh et al. 2013; Lau et al. 2013; Hsu et al. 2012), leading to more severe hydro-climatic extremes like floods, droughts and extreme events in future. However, the response of different regional monsoons to changing climate may vary due to distinctive land-ocean configuration, orography and forcing (Cherchi et al. 2011; Turner and Annamalai, 2012). Nevertheless, the future projections of regional monsoons still remain largely uncertain (IPCC 2007) and need more careful investigations.

The Indian summer monsoon (ISM) is one of the most energetic and vigorous regional monsoon systems and exhibits highly complex spatio-temporal variability during June-September (JJAS) (Goswami 2011). As the monsoon has strong sensitivity to global warming (Kitoh et al. 2013), it is expected that the unprecedented enhancement of GHG emissions in the recent times could rather aggravate the complexity and severity of ISM. Such potential consequences could amplify the extreme behaviour of ISM leading to disastrous impacts on the agricultural production, ecosystems, health and food security, agrarian-based economy over this subcontinent (e.g. Gadgil and RupaKumar 2006). The realistic projections on future behaviour of ISM variability are thus imperative for making sustainable economic development and better future adaptation measurements over largely populated Indian subcontinent.

Investigations involving the emerging effects of atmospheric warming on changing the dynamics and thermodynamics of ISM have already been started since late-twentieth century. Some observational studies show significant increase in the frequency of extreme precipitation events (Goswami et al., 2006; Rajeevan et al., 2008) and declining trend in 
lowto-moderate rainfall events and low level circulation associated with ISM over Indian subcontinent since 1950's (Dash et al., 2009). On contrary, the analysis of 131 years (18712001) observational data could not find any clear evidence of changes in ISM strength and its interannual variability (IAV) (Kripalani et al., 2003; Guhathakurta and Rajeevan, 2008). Recently, Ghosh et al. (2012) also found lack of uniform trends during the period of (19512003), but an increase in the spatial variability of observed rainfall extremes. However, in contrast, the recent study by Singh et al. (2014) demonstrated statistically significant changes in the extreme wet and dry spells in the recent decades by analyzing between two periods of the observed record (1951-1980) and (1981-2011). Hence, extensive debates still exist in understanding the possible modulation of the observed space-time characteristics of ISM variability and its provenance to climate change.

Climate models could be useful tools to simulate present climate and can provide quantitative estimates of the future climate variability. Over the last two decades, several modelling studies have been attempted to address this issue using different sensitivity experiments. On the seasonal scale, most of these studies suggested intensification of ISM rainfall in future warmer climate due to the anticipated increase in GHG concentrations (Meehl and Washington 1993; Hu et al. 2000; May 2004, 2011; Kripalani et al. 2007; Turner et al. 2007; Stowasser et al. 2009; Cherchi et al. 2010; Krishna Kumar et al. 2011). Despite future increase in monsoon rainfall, many studies are also suggestive of the weakening of both the cross-equatorial monsoon flow and tropical large scale overturning circulations in response to anthropogenic forcing (Kitoh et al. 1997; Douville et al. 2000; Tanaka et al., 2004; Ueda et al., 2006; Stowasser et al., 2009; Krishnan et al., 2013), which is popularly known as the precipitation-wind paradox (Ueda et al. 2006). Most of these modelling studies advocate the role of increased preferable thermodynamic conditions over ISM region for the intensification of monsoon rainfall leading to the 'wet-get-wetter' situation 
(Held and Soden, 2006) in response to greenhouse warming (Bhaskaran et al. 1995; Kitoh et al., 1997; Hu et al., 2000; Lal et al., 2001; May 2004, 2011; RupaKumar et al., 2006; Turner et al., 2007; Cherchi et al. 2010). The combination of warmer Indian Ocean and enhanced lowlevel moisture convergence have been found to play significant role in increasing monsoon rainfall despite the weakened south-westerly monsoon flow through reduction in meridional thermal gradient (Ueda et al. 2006; Dairaku and Emori, 2006; Meehl et al. 2007; Stowasser et al., 2009; Turner et al., 2011). In contrast, few other studies found drier monsoon due to the dominant future dynamical feedback in a warmer climate (Ashfaq et al. 2009; Annamalai et al. 2013). Some of the above studies also projected increase in IAV of monsoon rainfall in future climate (e.g. Hu et al. 2000; May 2004; Turner et al. 2007), while Turner et al (2007) found increased coupling between modelled IAV of monsoon rainfall and wind strength under future emission scenario, which appears highly uncertain. In addition, no clear suggestions have been made on the seasonal projection of future frequency and spatial changes in the extremes IAV of ISM; namely strong monsoon (SM) and weak monsoon (WM) seasons (Annamalai 2011). The presence of such uncertainties and lack of robustness among the models contribute to the large spread in the future ISM projection. Therefore, the projection of ISM on seasonal to interannual timescale still remains highly uncertain and regionally variable under warmer climate (Krishna Kumar et al. 2011; IPCC 2007).

On the other hand, very few studies have assessed the future projections of the monsoon intraseasonal variability (ISV). Within the ISM variability, the dominant intraseasonal (10-90 day mode) quasi-periodic monsoon intraseasonal oscillations (ISOs) are considered as the major building blocks of the ISM rainfall as they manifest in the form of active/break episodes over Indian subcontinent (Goswami 2011). The duration and frequency of these wet/dry spells within a monsoon season contributes to the seasonal 
mean rainfall, and thus modulates the IAV of ISM (Goswami 2011); e.g. prolonged actives/breaks during critical crop growth period severely damage the agricultural yields, and any possible change in response to GHG warming will cause cascading impacts on socioeconomic condition over India. Therefore, it is necessary to understand the possible response of monsoon ISOs and associated active-break cycles to the GHG warming. Based on the Coupled Model Intercomparison Project Phase 3 (CMIP3) multi-model dataset, Mandke et al. (2007) analyzed the sensitivity of active-break cycles in response to GHG forcing and found the break spells to intensify and extend in the future, however there were inconsistency among different scenarios of the same models. Turner and Slingo (2009) further noted an intensification of both active and break events relative to seasonal cycle, without any suggestion on any change to the duration or likelihood of monsoon breaks. However, precise assessments of such regional projections based on CMIP3 multi-models have remained highly uncertain due to variations among the model projections as well as the models' limited ability to simulate ISV of ISM.

Recently, the multi-model data archive of CMIP Phase 5 (CMIP5; Taylor et al., 2012) has been released in preparation of the Intergovernmental Panel on Climate change (IPCC) fifth assessment report (IPCC-AR5) under which a series of experiments including the $20^{\text {th }}$ century historical simulation and $21^{\text {st }}$ century climate projections with four different representative concentration pathway $(\mathrm{RCP})$ were performed using various coupled general circulation models (CGCMs) developed by a number of international climate modelling groups from around the world. Compared to CMIP3, the CMIP5 models are better in terms of representing model physics, resolutions, inclusion of atmospheric aerosols (Taylor et al., 2012; Sperber et al., 2012). Even some models are Earth System Models (ESMs) that include the changes in the earth climate system. The CMIP5 models are found to be far better than CMIP3 in representing Asian-Australian monsoon matrices (Wang et al. 2013). In addition, 
CMIP5 models project a larger increase in annual mean precipitation over the entire Asian monsoon region with less uncertainty than CMIP3 (Lee and Wang 2014). Therefore, the CMIP5 models can be utilised for better projection of the future ISM variability. Recent studies have already investigated the overall future changes in global monsoon precipitation using multi-model ensemble and/or selected CMIP5 models under different range of RCP scenarios (Hsu et al. 2012, 2013; Wang et al. 2013; Kitoh et al. 2013; Lee and Wang 2014), that suggest notable increase in global monsoon precipitation during 21st century due to global warming. However, by comparing the future projections between RCP4.5 (moderate) and RCP8.5 (strongest) scenarios, Kitoh et al (2013) suggested that the global monsoon response to atmospheric warming is larger and more robust in a warmer RCP8.5 world among the models. Motivated by these key issues, the present study utilizes the historical simulations of (1951-1999) and future projections of (2051-2099) under the strongest RCP8.5 scenario in an attempt to demonstrate a more robust future projection of ISM variability (from daily to sub-seasonal, and seasonal to interannual time scales) based on standard and careful diagnosis. Therefore, the main objectives of this study are: to evaluate the fidelity of around 20 CMIP5 models in simulating the basic features of ISM variability of the present climate and selection of most reliable models to investigate the potential future changes in ISM variability under the strongest RCP8.5 scenario emphasizing the emerging role of increased anthropogenic GHGs emissions in changing the future ISM.

The paper is organized as follows: The models, data and method used in the present study are described in Sect. 2. The future projections of ISM variability from CMIP5 models are discussed in Sect. 3 and Sect. 4 summarizes the important conclusions of this paper.

\section{Model, data and methodology}

\subsection{CMIP5 models and experiments}


To assess the future change in ISM under climate change scenario, the simulations from historical (1951-1999) and RCP8.5 (2051-2099) experiments are analyzed. The historical runs ( $20^{\text {th }}$ century simulations) are forced by observed transient climate forcings from the instrumental period (solar, volcanoes, GHGs concentrations, reconstructed aerosol emission etc). Initial conditions are based on a long equilibrium control run with fixed pre-industrial forcings. The RCP8.5 runs $\left(21^{\text {st }}\right.$ century simulations) are forced with relatively high anthropogenic GHGs emissions, designed so that anthropogenic radiative forcing will increase and then stabilize at about $8.5 \mathrm{Wm}^{-2}$ after 2100 . Initial conditions for the RCP8.5 scenario start from the end of the historical runs. Similar future projections under RCP4.5 scenario are also used for comparison. In this study, outputs from 20 CMIP5 models (Table 1) including daily precipitation, the zonal, meridional wind, vertical pressure velocity, temperature and specific humidity at all available levels of both experiments are used for analysis. For each model, only one ensemble member ( 1 1i1p1) run has been used (similar to Kitoh et al. 2013). More details on models and experiments can be found in Taylor et al. (2012). All model outputs are freely accessible at http://pcmdi9.Inl.gov/esgf-web-fe/ maintained by Earth System Grid Federation (ESGF).

Table 1 List of CMIP5 models selected for this study along with modelling groups and the horizontal/vertical resolution of the corresponding atmosphere/ocean models 


\begin{tabular}{|c|c|c|c|}
\hline CMIP5 Model & Modelling Group & AGCM resolu. & OGCM resolu. \\
\hline ACCESS1.0 & $\begin{array}{l}\text { Commonwealth Scientific and Industrial Research } \\
\text { Organization (CSIRO) and Bureau of Meteorology, } \\
\text { (BOM), Australia }\end{array}$ & $1.25^{\circ} \times 1.875^{\circ} \mathrm{L} 38$ & \\
\hline ACCESS1.3 & $\begin{array}{l}\text { Commonwealth Scientific and Industrial Research } \\
\text { Organization (CSIRO) and Bureau of Meteorology, } \\
\text { (BOM), Australia }\end{array}$ & $1.25^{\circ} \times 1.875^{\circ} \mathrm{L} 38$ & \\
\hline BCC-CSM1.1 & $\begin{array}{c}\text { Beijing Climate Centre, China Meteorological } \\
\text { Administration, China }\end{array}$ & T42L26 & $1 \times 1.33$ L40 \\
\hline BNU-ESM & $\begin{array}{c}\text { College of Global Change and Earth System Science, } \\
\text { Beijing Normal University, China }\end{array}$ & T42L26 & \\
\hline CanESM2 & $\begin{array}{l}\text { Canadian Centre for Climate Modelling and Analysis, } \\
\text { Canada }\end{array}$ & T63L35 & $256 x 192 \mathrm{~L} 40$ \\
\hline CSIRO-Mk3.6.0 & $\begin{array}{l}\text { Commonwealth Scientific and Industrial Research } \\
\text { Organization in collaboration with the Queensland } \\
\text { Climate Change Centre of Excellence, Australia }\end{array}$ & T63L18 & $\begin{array}{l}1.875 x^{\sim} 0.9375 \\
\text { L31 }\end{array}$ \\
\hline GFDL-CM3 & Geophysical Fluid Dynamics Laboratory, USA & $2^{u} \times 2.5^{u} \mathrm{~L} 48$ & $360 \times 200$ L50 \\
\hline GFDL-ESM2G & Geophysical Fluid Dynamics Laboratory, USA & $2 \times 2.5^{0} \mathrm{~L} 24$ & $360 \times 210$ L63 \\
\hline GFDL-ESM2M & Geophysical Fluid Dynamics Laboratory, USA & $2^{u} \times 2.5^{u} \mathrm{~L} 24$ & $360 \times 200$ L50 \\
\hline HadGEM2-ES & Met Office Hadley Centre, UK & $1.25^{\circ} \times 1.875^{\circ} \mathrm{L} 38$ & $1 \times 0.3-1.0\llcorner 40$ \\
\hline INMCM4 & Institute for Numerical Mathematics, Russia & $1.5^{\circ} \times 2.0^{\mathrm{u}} \mathrm{L} 21$ & $1 \times 0.5$ L40 \\
\hline IPSL-CM5A-LR & Institut Pierre-Simon Laplace, France & $1.875^{\circ} \times 3.75^{\circ}$ L39 & $2 \times 2$ L31 \\
\hline IPSL-CM5A-MR & Institut Pierre-Simon Laplace, France & $1.25^{\mathrm{u}} \mathrm{X} 2.5^{\mathrm{u}} \mathrm{L} 39$ & $2 \times 2$ L31 \\
\hline IPSL-CM5B-LR & Institut Pierre-Simon Laplace, France & $1.875^{\circ} \times 3.75^{\circ}$ L39 & \\
\hline MIROC5 & $\begin{array}{l}\text { Atmosphere and Ocean Research Institute (The } \\
\text { University of Tokyo), National Institute for } \\
\text { Environmental Studies, and Japan Agency for } \\
\text { Marine-Earth Science and Technology }\end{array}$ & T85L40 & $256 \times 224$ L50 \\
\hline $\begin{array}{l}\text { MIROC-ESM- } \\
\text { CHEM }\end{array}$ & $\begin{array}{l}\text { Japan Agency for Marine-Earth Science and } \\
\text { Technology, Atmosphere and Ocean Research } \\
\text { Institute (The University of Tokyo), and National } \\
\text { Institute for Environmental Studies, Japan }\end{array}$ & T42L80 & $256 \times 192$ L44 \\
\hline MPI-ESM-LR & $\begin{array}{c}\text { Max Planck Institute for Meteorology (MPI-M), } \\
\text { Germany }\end{array}$ & T63L47 & GR15 L40 \\
\hline MPI-ESM-MR & $\begin{array}{l}\text { Max Planck Institute for Meteorology (MPI-M), } \\
\text { Germany }\end{array}$ & T63L95 & \\
\hline MRI-CGCM3 & Meteorological Research Institute , Japan & T159L48 & $256 \times 192$ L44 \\
\hline NorESM1-M & Norwegian Climate Centre, Norway & $1.875^{\circ} \times 2.5^{0}$ & $384 \times 320$ L53 \\
\hline
\end{tabular}

\subsection{Datasets used}

To validate the CGCMs in their historical simulations with respect to observations in terms of daily precipitation, observed high resolution daily gridded rainfall data over Indian land region from National Climate Centre (NCC), India Meteorological Department (IMD), Pune (Rajeevan et al., 2006), and satellite based daily Global Precipitation Climatology Project (GPCP) precipitation data (Huffman et al., 2009) are used. The reanalysis data of daily circulation from National Centers for Environmental Prediction/National Center for 
Atmospheric Research (NCEP/NCAR; Kalnay et al. 1996) are also used for calculating longterm dynamical monsoon indices.

\subsection{Methodology}

All model outputs are interpolated into common $2.5^{\circ} \times 2.5^{\circ}$ grid by bilinear interpolation. The overall fidelity of each model to simulate seasonal mean ISM and its variability of the present climate is assessed using Taylor diagram metric (Taylor, 2001). Taylor diagrams are well accepted performance metrics for climate models that provide a brief statistical outline of how well spatial/temporal patterns match each other in terms of their correlation coefficients (CC), their root-mean-square error (RMSE), and the simulated to observed ratio of their variances. The distance from the origin indicates the normalized standard deviation (NSD) of each model. Using this metric, the model having the largest CC, normalized standard deviation close to the unity (i.e; close to the observation) and smaller RMSE is considered to be the best among them.

The IAV of ISM strength is analyzed using multiple summer monsoon indices. The allIndia Rainfall (AIR) index (from JJAS rainfall area-averaged over Indian land points) and different dynamical monsoon indices (DMIs) are computed for all selected models to make projection on the future association between rainfall and wind strength on interannual time scales. The three DMIs related to wind shear have been used: (1) vertical shear of zonal wind (WY Index; Webster and Yang, 1992), (2) horizontal shear of zonal wind (WF Index; Wang and Fan, 1999) and (3) vertical shear of meridional wind (MH Index; Goswami et al 1999). Further, the extremes of IAV; i.e. strong (SM) and weak (WM) monsoon are identified when AIR $\geq+1.0$ and $\leq-1.0$ respectively.

The daily anomalies are computed by subtracting daily smoothed (mean +1 st three harmonics) long term climatology for all the datasets. To understand the space-time behaviour of monsoon ISOs, limited domain meridional wavenumber frequency spectra 
analysis (following Wheeler and Kiladis, 1999 and Joseph et al. 2012) is performed on daily precipitation during May to October over ISM region. To extract dominant ISV of ISM, Lanczos filter (Duchon 1979) has been applied on daily anomalies. An extended empirical orthogonal function (EEOF) analysis is also performed on intraseasonally filtered daily precipitation over ISM domain $\left(15^{\circ} \mathrm{S}-30^{\circ} \mathrm{N}\right.$ and $\left.65^{\circ}-95^{\circ} \mathrm{E}\right)$ during June to September to extract the monsoon ISO evolution. The 30-70day filtered daily precipitation is then lagregressed onto first EEOF mode to capture the dominant northward propagating monsoon ISOs for all the simulations. In addition, to identify the active-break cycles associated with monsoon ISV, a rainfall index (RI) is computed by applying a 10-90 day band-pass filter to the daily rainfall anomalies area-averaged over core monsoon zone (similar to Rajeevan et al., 2010) for each year normalized by its own standard deviation. The active (break) spells are identified such that $\mathrm{RI}>+1.0(<-1.0)$ for at least consecutive 3 days or more for all the years. The Identification procedure is done from 15 June to 20 September of each year.

Further, the daily equivalent potential temperature $(\theta e)$, atmospheric dry static stability, moisture convergence flux are also computed for both simulations to investigate the change in thermodynamic conditions in response to enhanced GHG induced warming.

\section{Results and discussions}

\subsection{Model Selection}

Before projecting the possible future changes, it is essential to evaluate the fidelity of these CMIP5 CGCMs in simulating observed ISM and its variability. All 20 CGCMs may not represent ISM realistically and hence their projection will be more or less uncertain. Hence, instead of creating a multi-model ensemble of all available CMIP5 models, the usage of better climate models in terms of their performance in simulating realistic ISM variability would be beneficial for making reliable projections. Therefore, a set of six performance 
metrics has been employed in choosing better models compared to observations (OBS hereafter). The evaluation metrics includes spatial/temporal patterns of (1) climatological seasonal (JJAS) mean precipitation over Indian land points [IND region], (2) JJAS mean precipitation over Indian summer monsoon region $\left[15^{\circ} \mathrm{S}-30^{\circ} \mathrm{N} ; 50^{\circ}-120^{\circ} \mathrm{E}, \mathrm{ISM}\right.$ region], (3) JJAS standard deviation of precipitation over extended IND region, (4) mean seasonal cycle over IND region, (5) mean seasonal migration of daily precipitation over Indian longitude $\left[65^{\circ}-95^{\circ} \mathrm{E}\right]$ and $(6)$ the intraseasonal (10-90-day filtered) variance of June-September daily precipitation over ISM region using Taylor diagrams (Figure 1; method briefly discussed in Sec. 2.3).
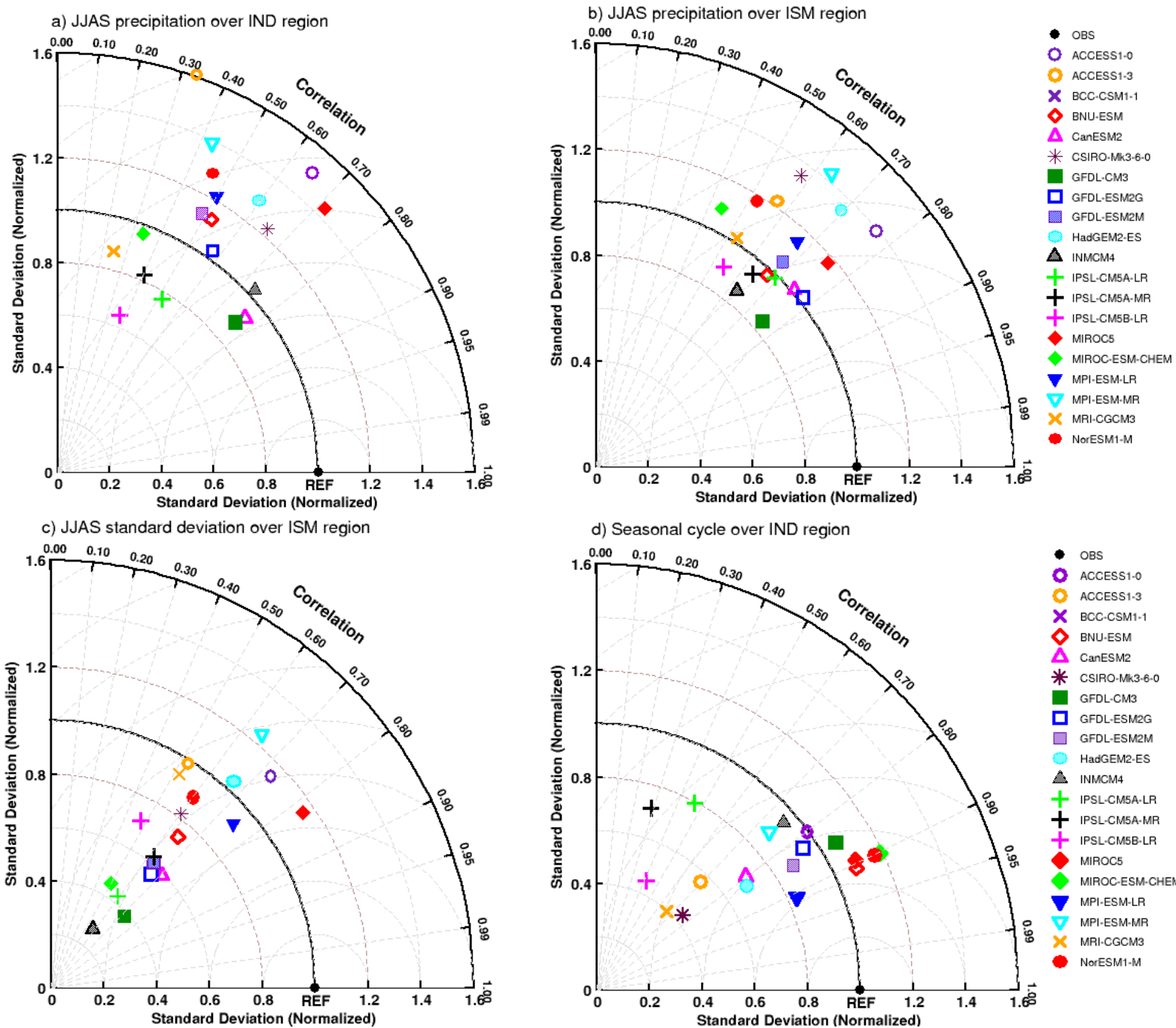

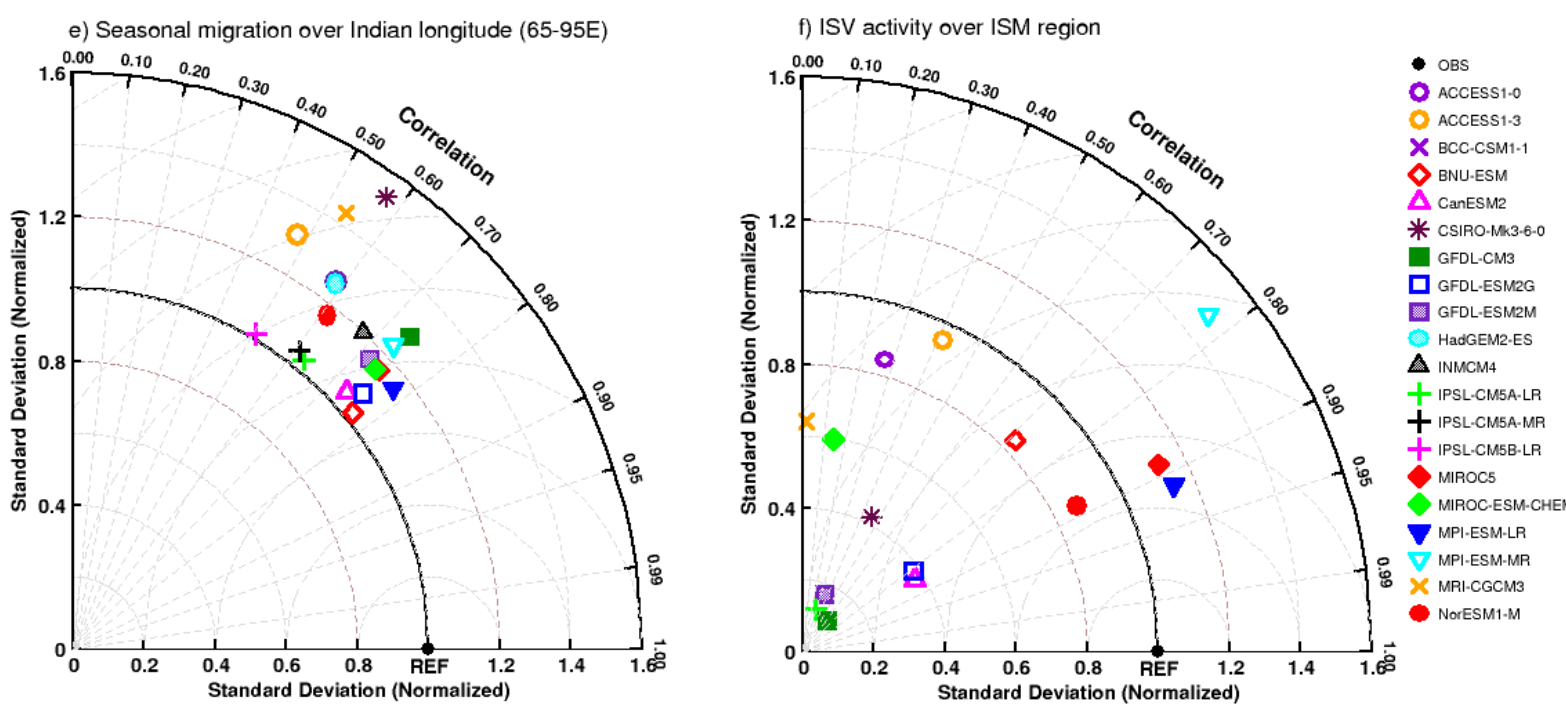

Figure 1 Selection of better CMIP5 models using Taylor diagrams: a) climatological seasonal mean (JJAS) precipitation over IND region (Indian land points only), b) JJAS mean precipitation over Indian monsoon region $\left[15^{\circ} \mathrm{S}-30^{\circ} \mathrm{N} ; 50^{\circ}-120^{\circ} \mathrm{E}\right.$, c) JJAS standard deviation of precipitation over Indian subcontinent, d) mean seasonal cycle (May to October) over IND region, e) mean seasonal migration of precipitation over Indian longitude $\left(65^{\circ}-95^{\circ} \mathrm{E}\right)$, and f) mean ISV variance of 10-90 day filtered daily JJAS precipitation anomalies over Indian monsoon region $\left[15^{\circ} \mathrm{S}-30^{\circ} \mathrm{N} ; 50^{\circ}-120^{\circ} \mathrm{E}\right.$ ] simulated by 20 models and their comparison with observation.

We define the criteria for the performance metrics as models having at least $C C>=0.5$ and $0.8 \leq N S D \leq 1.2$ in simulating most of the above features of ISM and its variability. From Figure 1a, it seems that simulating the spatial pattern of JJAS precipitation perfectly over IND region compared to IMD rainfall is still a difficult task for most of the models. Only GFDL-CM3, CanESM2, INMCM4, GFDL-ESM2G are able to reproduce it to some extent. However, over ISM region many models could capture the observed spatial patterns having CC $>0.65$ (Figure 1b). Taylor diagram of the JJAS standard deviation of precipitation (Figure 1c) shows that MIROC5, MPI-ESM-LR, HadGEM2-ES, ACCESS1-0, NorESM1-M perform better than others, while in simulating May to October seasonal cycle of daily precipitation (Figure 1d), mainly ACCESS1-0, BNU-ESM, MIROC5, MIROC-ESM-CHEM, MPI-ESM-LR, MPI-ESM-MR, NorESM1-M and all GFDL models perform well. Figure 1e shows that most of the models (except ACCESS1-3, BCC-CSM1-1, CSIRO-Mk3-6-0, HadGEM2-ES, MRI-CGCM3) simulate the seasonal migration of daily rainfall over Indian region reasonably. However, most 
importantly, only BNU-ESM, MPI-ESM-LR, MIROC5 and NorESM1-M could simulate the spatial pattern of intraseasonal variance over ISM region reasonably compared to GPCP (Figure 1f). Therefore, based on our model performance criteria, only 4 models (BNU-ESM, MPI-ESM-LR, MIROC5 and NorESM1-M) are found to be better among all 20 models in simulating ISM and its variability (Table 2).

Table 2 Model performance criteria used to select better CMIP5 models in simulating basic characteristics of Indian summer monsoon for this study. Selected models are highlighted in bold.

\begin{tabular}{|c|c|c|c|c|c|c|c|}
\hline \multirow[b]{2}{*}{ CMIP5 Models } & \multicolumn{3}{|c|}{ Rainfall simulation (Historical) } & \multicolumn{3}{|c|}{ Criteria : $C C \geq 0.5$ and $0.8 \leq N S D \leq 1.2$} & \multirow[b]{2}{*}{$\begin{array}{c}\text { Total } \\
\text { (out of } 6 \text { ) }\end{array}$} \\
\hline & $\begin{array}{l}\text { JJAS } \\
\text { (IND) }\end{array}$ & $\begin{array}{l}\text { JJAS } \\
\text { (ISM) }\end{array}$ & $\begin{array}{c}\text { JJAS std } \\
\text { dev. }\end{array}$ & $\begin{array}{c}\text { Seasonal } \\
\text { cycle }\end{array}$ & $\begin{array}{l}\text { Seasonal } \\
\text { migration }\end{array}$ & ISO Variance & \\
\hline ACCESS1-0 & - & - & + & + & - & - & 2 \\
\hline ACCESS1-3 & - & - & + & - & - & - & 1 \\
\hline BCC-CSM1-1 & - & - & - & - & - & - & 0 \\
\hline BNU-ESM & + & + & - & + & + & + & 5 \\
\hline CanESM2 & + & + & - & - & + & - & 3 \\
\hline CSIRO-Mk3-6-0 & - & - & + & - & - & - & 1 \\
\hline GFDL-CM3 & + & + & - & + & - & - & 3 \\
\hline GFDL-ESM2G & + & + & - & + & + & - & 4 \\
\hline GFDL-ESM2M & - & + & - & + & + & - & 3 \\
\hline HadGEM2-ES & - & - & + & - & - & - & 1 \\
\hline INMCM4 & + & + & - & + & + & - & 4 \\
\hline IPSL-CM5A-LR & - & + & - & - & + & - & 2 \\
\hline IPSL-CM5A-MR & - & + & - & - & + & - & 2 \\
\hline IPSL-CM5B-LR & - & + & - & - & + & - & 2 \\
\hline MIROC5 & - & + & + & + & + & + & 5 \\
\hline MIROC-ESM-CHEM & - & - & - & + & + & - & 2 \\
\hline MPI-ESM-LR & - & + & + & + & + & + & 5 \\
\hline MPI-ESM-MR & - & + & - & + & - & - & 2 \\
\hline MRI-CGCM3 & - & - & - & + & - & - & 1 \\
\hline NorESM1-M & - & + & + & + & + & + & 5 \\
\hline
\end{tabular}

Interestingly 3 out 4 models are the ESMs, therefore, providing more promise over other CGCMs. Recent studies also show that NorESM1-M and MIROC5 have the largest skill 
score in simulating mean state of global as well as Asian-Australian monsoon (Wang et al. 2014; Lee and Wang 2014), and MPI-ESM-LR have large skill score on intraseasonal timescales (Sperber et al. 2012). Sabeerali et al. (2013) noted that BNU-ESM, MIROC5, and MPI-ESM-LR are better in simulating realistic boreal summer ISOs variance over extended monsoon region. Figure 2 shows the simulated present climate evolution of the seasonal cycle of daily precipitation over IND region, where only the best 4 models and their mean (B4MMM hereafter) are shown in colour with respect to observation (black). Although MIROC5 (MPI-ESM-LR) slightly overestimates (underestimates) the rainfall magnitude possibly due to wet (dry) bias over central Indian region, it is noted that all best 4 models together with B4MMM reproduce the present-climate seasonal cycle quite realistically relative to OBS. In the following subsections, the projections of ISM variability using these models are shown systematically.

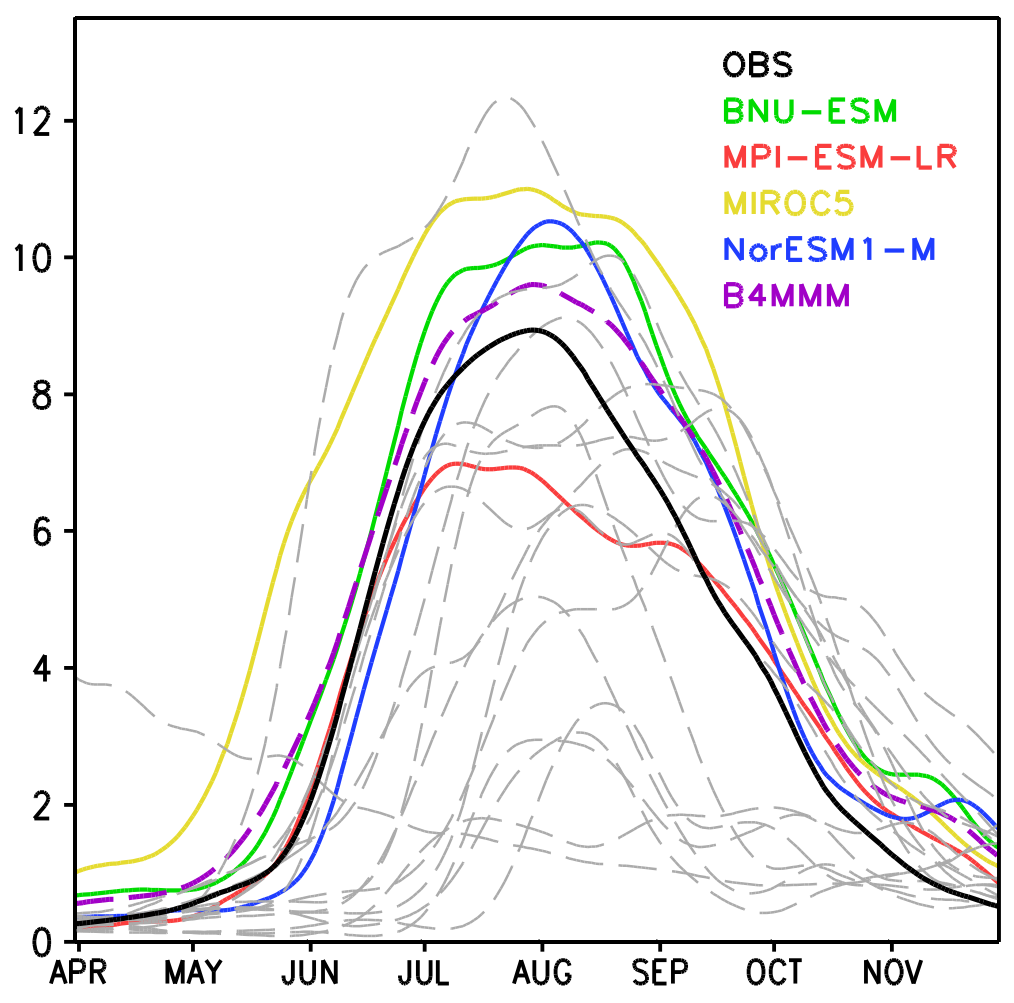

Figure 2 Seasonal cycle of daily precipitation over Indian land region from observation (IMD; Black) and 20 CMIP5 model simulations (historical). The selected models and their MMM are shown in colour. 


\subsection{Projected changes in seasonal mean state of ISM}

The projected seasonal cycle of daily precipitation over central Indian region under moderate RCP4.5 (dash blue curve) and strongest RCP8.5 scenarios (solid red curve) with respect to present climate (green curve), along with their changes are initially assessed and shown in Figure 3. Substantial potential increase in the rainfall maxima and length of summer monsoon season are projected in changing climate under both the scenarios (Figure 3a). Further, B4MMM suggests that rainfall magnitude is likely to increase in future and the duration of the rainy season may also lengthen due to delayed withdrawal, although not much changes in monsoon onset is expected (Figure 3a). Figure $\mathbf{3 b}$ further demonstrates that the likelihood of future changes in both magnitude and evolution is more robust and consistent among the selected models under RCP8.5 scenario compared to RCP4.5 as suggested by previous studies (Kitoh et al. 2013). Hence, the present study further assesses the future changes in ISM variability under the RCP8.5 scenario only.

a) Future projection of seasonal cycle over $\mathrm{Cl}$
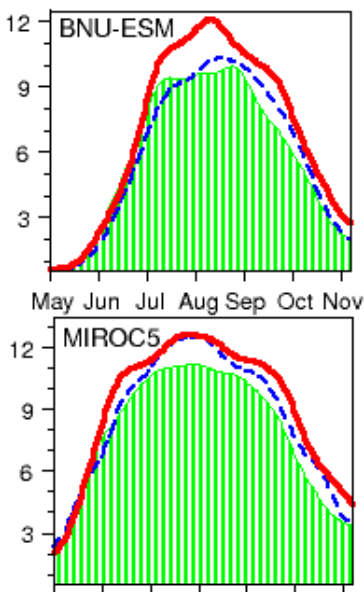

May Jun Jul Aug Sep Oct Nov May Jun Jul Aug Sep Oct Nov

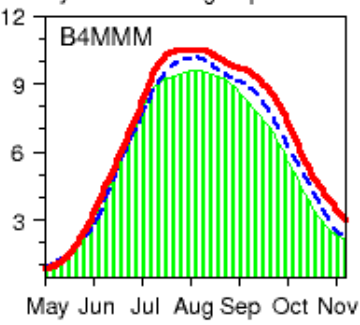

b) Anticipated change in seasonal cycle
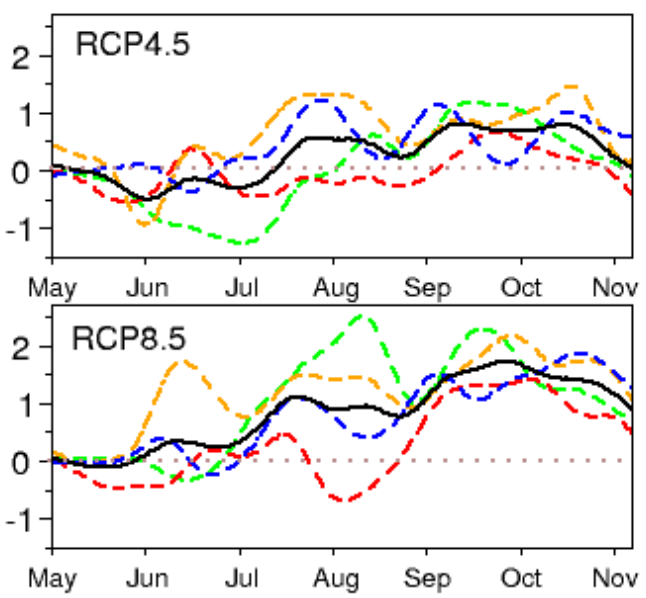

$$
\begin{array}{ll}
-- & \text { BNU-ESM } \\
-- & \text { MPI-ESM-LR } \\
-- & \text { MIROC5 } \\
-- & \text { NorESM1-M } \\
- & \text { B4MMM }
\end{array}
$$

Figure 3 (a) Present climate (historical; green curve) and projected future changes in mean seasonal cycle of daily precipitation over central Indian region (Cl) under RCP4.5 (blue; dash 
curve) and RCP8.5 (red; solid curve) scenarios for selected CMIP5 models and their MMM. The anticipated changes in seasonal cycles are shown in (b).

The projected relative spatial changes in the spatial pattern of seasonal mean rainfall over ISM region are shown in Figure 4a-e. Model projections indicate that the JJAS mean precipitation will enhance about $10-25 \%$ over Indian subcontinent (Fig 4 a-e) relative to present climate. However, MPI-ESM-LR shows a decreased rainfall over north-west Indian region and adjoining northern Arabian Sea. The B4MMM projects overall increased rainfall over central-west to peninsular Indian region as well as most part of ISM region; but rainfall increase over the eastern region is not very remarkable. In addition, a slight decrease over head Bay of Bengal and substantial suppression of rainfall over the east equatorial Indian Ocean (EEIO) are also projected. It is noteworthy that a north-south asymmetry in the JJAS mean rainfall over ISM region is evident in the models. To understand the projected dynamical and thermo-dynamical feedbacks associated with the rainfall change, the change in seasonal mean low-level circulation (vector) overlaid with vertically integrated (surface to $500 \mathrm{hPa}$ ) moisture convergence flux (shaded) are presented in Fig. 4f-j. In addition, the JJAS change in vertical pressure velocity (omega) at $500 \mathrm{hPa}$ (shaded) overlaid with specific humidity at $850 \mathrm{hPa}$ (contour) is also shown in Fig. 4k-o for selected models. The B4MMM shows that the general increase in ISM rainfall may be primarily driven by the intensified low level moisture convergence (Fig $\mathbf{4 j}$ ) due to considerable enhancement of atmospheric moisture content (Fig. 4o) over ISM region in response to increased GHG warming. However, local change in moisture convergence varies geographically over Indian subcontinent; e.g. it is projected that the moisture convergence will be reduced over the regions of least intense rainfall, i.e.; northwest India and north-east India. This may be related to the difference in the dynamical feedback change over ISM region in future climate. Projections on low level monsoon circulation changes show weakening of the cross- 
equatorial westerlies (Fig. 4j) over Arabian Sea with the northward shift of the moisture flux. The large decrease of rainfall over EEIO may be related to the projected strong subsidence from the enhanced convection over warmer Western Pacific connected through an overturning circulation (Fig. $\mathbf{4 e}$ and 4o). A pair of anticyclones in the lower level (one over the Bay of Bengal and another over $10^{\circ} \mathrm{S}$ of EIO) are projected as Rossby wave response to the largely decreased rainfall over EEIO. These projected circulation change along with westward shift of extended anticyclonic circulation from North-Western Pacific may strengthen the easterly anomaly along the EIO, resulting in the weakening of the cross equatorial seasonal mean low level circulation, consistent with previous studies (Stowasser et al. 2009; May et al. 2011). Also an anomalous anticyclonic circulation is collocated around $10-15^{\circ} \mathrm{N}$ (Fig. 4j) along with low level humidity maxima near the west coast of Indian subcontinent over warmer Indian Ocean (Fig. 4o). Such changes in local circulation may enhance local evaporation that favours the intensification of JJAS mean rainfall over these regions. It is noted that the increased ISMR may be mainly driven by the enhanced moisture flux, while the dynamical processes associated with the changes in vertical motion (Fig. 40) may tend to suppress the increase in rainfall over south-eastern zone. In addition, Table 3 documents the simulated present climate JJAS mean ISMR from the selected models and B4MMM compared to OBS along with their future estimation of projected ISMR under RCP8.5 scenario. It is noted that the B4MMM well agrees with OBS in simulating present climate ISMR and its interannual standard deviation (SD). However, there are some variations among the individual selected models. e.g. MPI-ESM-LR reasonably underestimates the ISMR due to dry bias over central India, but model simulates the seasonal cycle and ISV quite realistically. The future projection (2051-2099) from B4MMM compared with present climate (1951-1999) suggests increased ISMR and SD in future climate. 


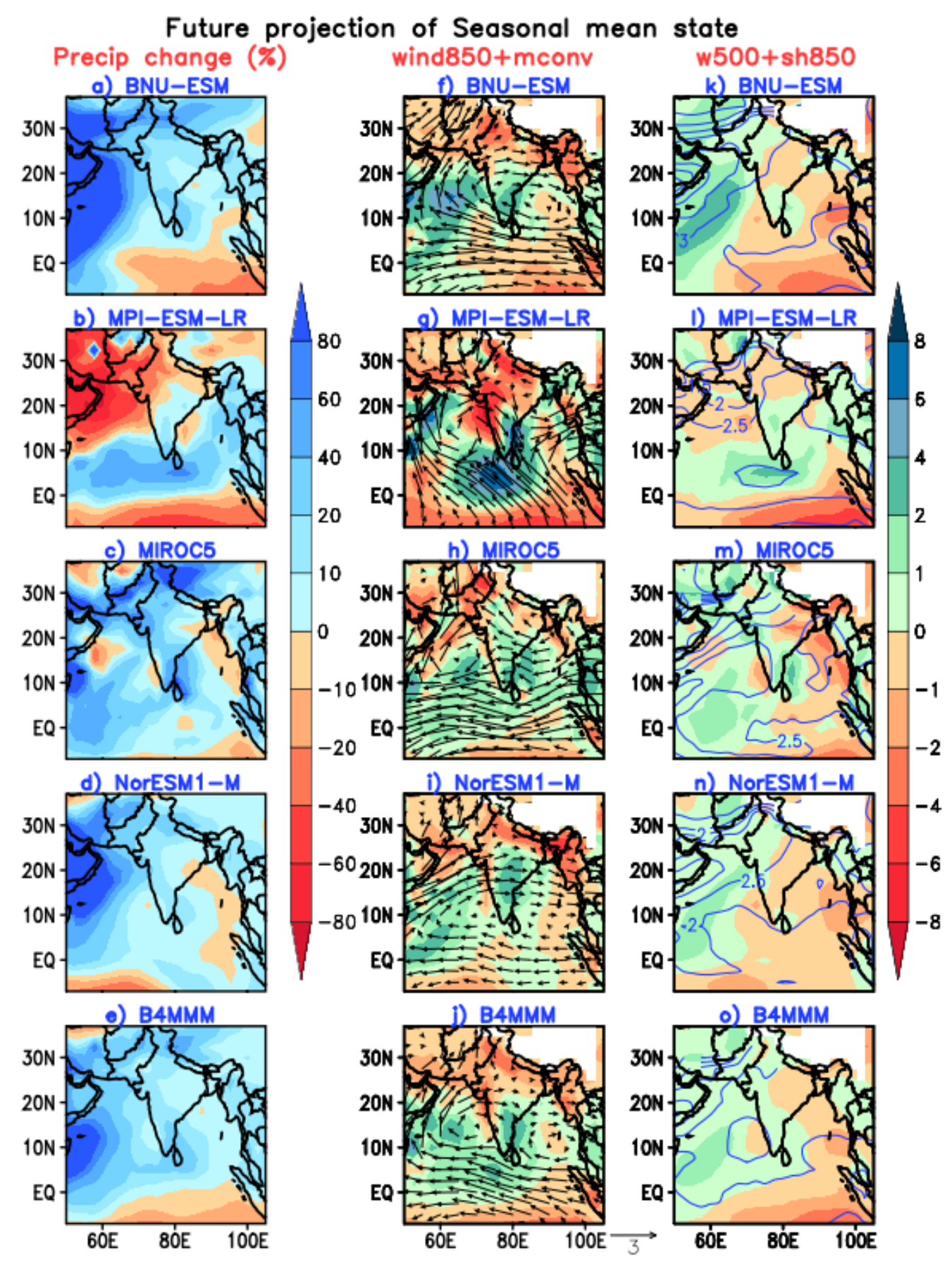

Figure 4 Projected spatial changes in the seasonal mean state of ISM under RCP8.5 scenario: Relative changes ${ }^{a}(\%)$ in JJAS rainfall are shown in a-e, changes (RCP8.5 -Hist) to the low level circulation (850 $\mathrm{hPa}$; vector) and vertically integrated (surface to 500hPa) moisture convergence flux (shaded) are shown in $f-j$, and changes to omega (at $500 \mathrm{hPa}$; shaded; positive values represents ascending motion) and specific humidity (at 850hPa; contour) are shown in $k-0$ for the selected CMIP5 models and their MMM. The changes are calculated between the period 2051-2099 and 1951-1999. ${ }^{a}\left(X_{R C P 8.5} X_{\text {Hist }}\right) / X_{\text {Hist }}$ 
Table 3 simulated mean all-India summer monsoon rainfall (ISMR) and interannual standard deviation (SD) and corresponding projected change under RCP8.5 scenario for selected models.

\begin{tabular}{|c|c|c|c|c|}
\hline Model & \multicolumn{2}{|c|}{ Historical (1951-1999) } & \multicolumn{2}{c|}{ RCP8.5 (2051-2099) } \\
\hline & Mean & SD & Mean & SD \\
\hline Observed & $\mathbf{8 5 6 . 1 4}$ & $\mathbf{8 5 . 3 5}$ & - & - \\
\hline BNU-ESM & 810.73 & 70.86 & 938.54 & 82.85 \\
\hline MPI-ESM-LR & 642.33 & 59.86 & 656.69 & 78.68 \\
\hline MIROC5 & 1013.24 & 85.82 & 1149.04 & 82.23 \\
\hline NorESM1-M & 882.60 & 89.03 & 971.85 & 91.73 \\
\hline B4MMM & $\mathbf{8 3 7 . 2 3}$ & $\mathbf{7 6 . 3 9}$ & $\mathbf{9 2 9 . 0 3}$ & $\mathbf{8 3 . 8 7}$ \\
\hline
\end{tabular}

Figure 5 further abstracts the contributing factors for the projected changes in rainfall over ISM domain under climate change scenario. The low level specific humidity averaged over Indian longitude $\left(65^{\circ}-95^{\circ} \mathrm{E}\right)$ shows significant increase over ISM domain due to anthropogenic global warming (Figure 5a), thereby remarkably enhance the atmospheric instability throughout the column as evident from the change in vertically averaged equivalent potential temperature ( $\theta$ e) (Figure 5b). This will further favour the projected increase in rainfall over ISM domain (Figure $\mathbf{5 c}$ ). However, the rainfall change is not sufficiently as large as the remarkable change in thermo-dynamical conditions, probably offset by the weakened vertical easterly shear over equatorial region (Figure $\mathbf{5 d}$ ). The projected weakening of the monsoon circulation may be related to the gradual reduction of dry static stability in both upper (Figure 5e) and lower troposphere (Figure 5f), thereby stabilizing the atmosphere throughout the summer season in future, which is an opposing effect of GHG-induced warming. Such changes in feedback between dynamics and moist processes in response to climate change may further modify the rainfall evolution over the ISM domain. 

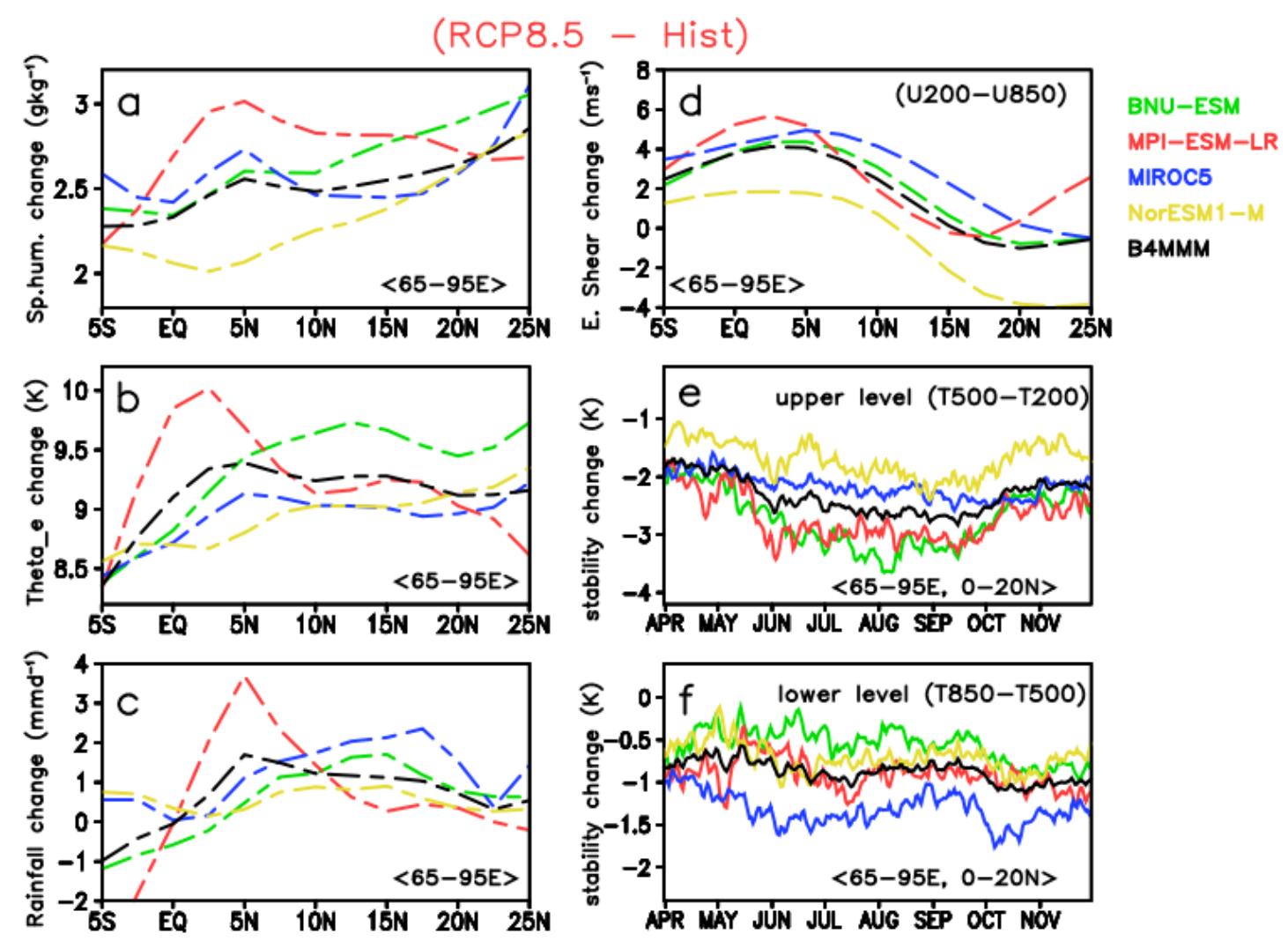

Figure 5 Projected changes (RCP8.5 - Hist) [(2051-2099) minus (1951-1999)] in the meridional distribution of $\boldsymbol{a}$. specific humidity at $850 \mathrm{hPa}, \boldsymbol{b}$. vertically averaged equivalent potential temperature (or atmospheric instability), c. rainfall change, and d. vertical easterly shear $\left(U_{200}-U_{850}\right)$ averaged over Indian longitude $\left(65^{\circ}-95^{\circ} \mathrm{E}\right)$. The seasonal evolution of projected changes in the atmospheric dry static stability (at upper level $T_{500}-T_{200}$ and lower level $\left.T_{850^{-}}-T_{500}\right)$ over Indian monsoon region $\left(65^{\circ}-95^{\circ} \mathrm{E}, 0^{\circ}-20^{\circ} \mathrm{N}\right)$ are also shown in $e$. and $f$. respectively for the selected models and their MMM.

\subsection{Future changes in interannual variability of ISM}

In addition to the changes in the future mean ISM, the future estimates of year-to-year variability of ISM and the occurrence of SM/WM associated with extreme IAV are of great importance due to their potential consequences. Moreover, Sharmila et al. (2014) have recently shown that the observed seasonal mean states of SM and WM are distinctly different and could considerably modulate the ISV of ISM. Therefore, it will be worthwhile to make reliable estimates of their future changes. The IAV of ISM strength can be measured by the AIR index and different DMIs discussed in Sec. 2.3. Table 4 shows the 
correlation between AIR and three DMIs in the present climate compared to OBS and their future projections.

Table 4 Correlation between Indian summer monsoon rainfall Index and dynamical indices and its future projection under RCP8.5 scenario

\begin{tabular}{|c|c|c|c|c|}
\hline Experiment & Model & WY index & WF Index & MH Index \\
\hline Observed (1951-1999) & - & $\mathbf{0 . 5 3}$ & $\mathbf{0 . 7 8}$ & $\mathbf{0 . 6 8}$ \\
\hline Historical (1951-1999) & BNU-ESM & 0.29 & 0.72 & 0.49 \\
& MPI-ESM-LR & 0.41 & 0.64 & 0.61 \\
& MIROC5 & 0.12 & 0.39 & 0.67 \\
& NorESM1-M & 0.28 & 0.80 & 0.68 \\
& B4MMM & $\mathbf{0 . 2 8}$ & $\mathbf{0 . 6 5}$ & $\mathbf{0 . 6 1}$ \\
\hline \multicolumn{5}{|c}{} \\
\hline \multicolumn{5}{|c}{} \\
Future Projection (RCP8.5) & BNU-ESM & -0.47 & 0.52 & 0.35 \\
& MPI-ESM-LR & 0.15 & 0.74 & 0.52 \\
& MIROC5 & -0.24 & 0.44 & 0.36 \\
& NorESM1-M & 0.19 & 0.55 & 0.48 \\
& B4MMM & $-\mathbf{0 . 0 9}$ & $\mathbf{0 . 5 6}$ & $\mathbf{0 . 4 3}$ \\
\hline
\end{tabular}

It is evident that B4MMM well represents the present climate relationship of AIR with $\mathrm{WF}$ index and $\mathrm{MH}$ index compared to $\mathrm{OBS}$, while it underestimates the association between AIR and WY index to some extent. It is projected that the future correlations between DMIs and AIR might be highly reduced on interannual timescale, following the future weakening of the large scale circulation associated with enhanced ISMR in a warmer climate. It appears from the results that DMls may not be appropriate measures of future ISM strength in terms of precipitation, consistent with previous results (Kitoh et al. 1997; Dairamu and Emori, 2006). Therefore, the possible changes to IAV of ISM due to climate change are examined here using AIR index only. Then the percentages of occurrence of extreme monsoon years (i.e. SM and WM) are calculated for each simulation.

Figure 6 further shows the relative changes to the IAV of ISM due to increased GHGs under RCP8.5 scenario. B4MMM projects $>30 \%$ increase (relative to present climate) in both SM and WM in future climate. Although the percentage change is variable among the models; the sign of tendency is robust. The results suggest that IAV of ISM might enhance in 
response to increased GHG emissions in future climate, i.e. both the SM and WM years will be more frequent.

Relative change (\%) in Extreme Monsoon

Future climate (2051-2099) vs Present climate (1951-1999)

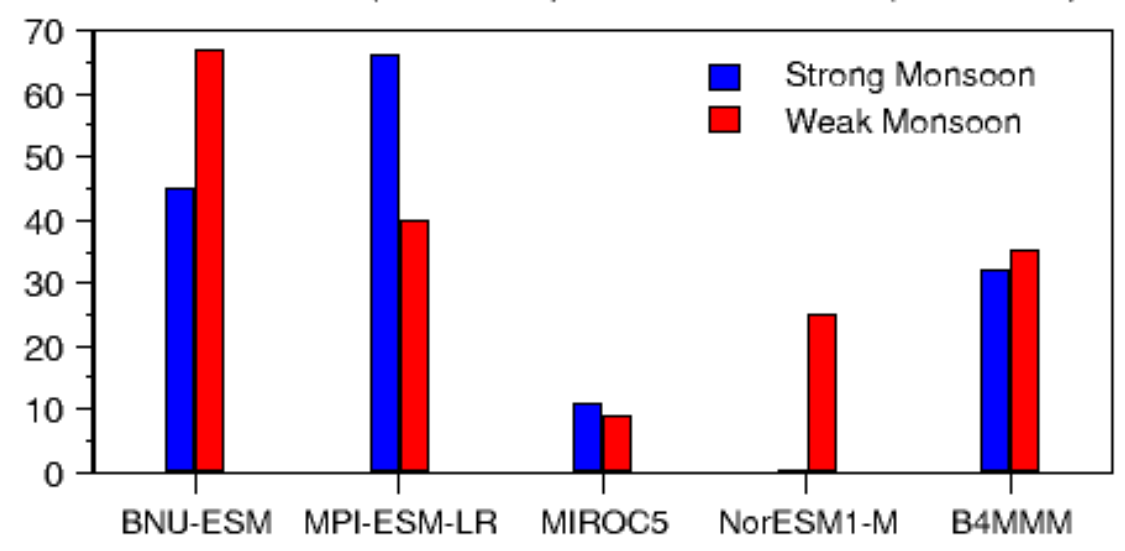

Figure 6 Future projection of relative changes (\%) in the extreme monsoon years: Strong monsoon (Blue) and Weak monsoon (Red) for selected models and their MMM

To understand the possible spatial changes of seasonal rainfall during extreme monsoons, the composited seasonal mean precipitation during SM and WM of present climate along with future projections under RCP8.5 scenario are constructed for all the models. Figure 7 shows the projected future changes (RCP8.5 - Hist) in seasonal mean rainfall (mm/day) during SM (left column) and WM (right column) for the selected models. The projected change indicate notable local enhancement of rainfall over monsoon core region and spatial expansion of the positive (negative) rainfall anomaly during SM (WM) over the Indian land as well as over adjoining oceanic regions. It is anticipated that the JJAS mean SM (WM) will be wetter (drier) over the core monsoon zone in the future compared to the present climate. However, the projected change in JJAS rainfall is geographically variable among the models. Previous studies found that the severe WM and SM are mostly associated with the developing phase of El-Nino Southern Oscillations (ENSO) (Pillai and Annamalai, 2011). Therefore, more occurrences of such extreme monsoons in future could 
be related to the frequency doubling of ENSO events as projected in CMIP5 (Cai et al., 2014) and which will be investigated further in future study. The possible changes to ISV during SM and WM will be discussed in the later subsection.

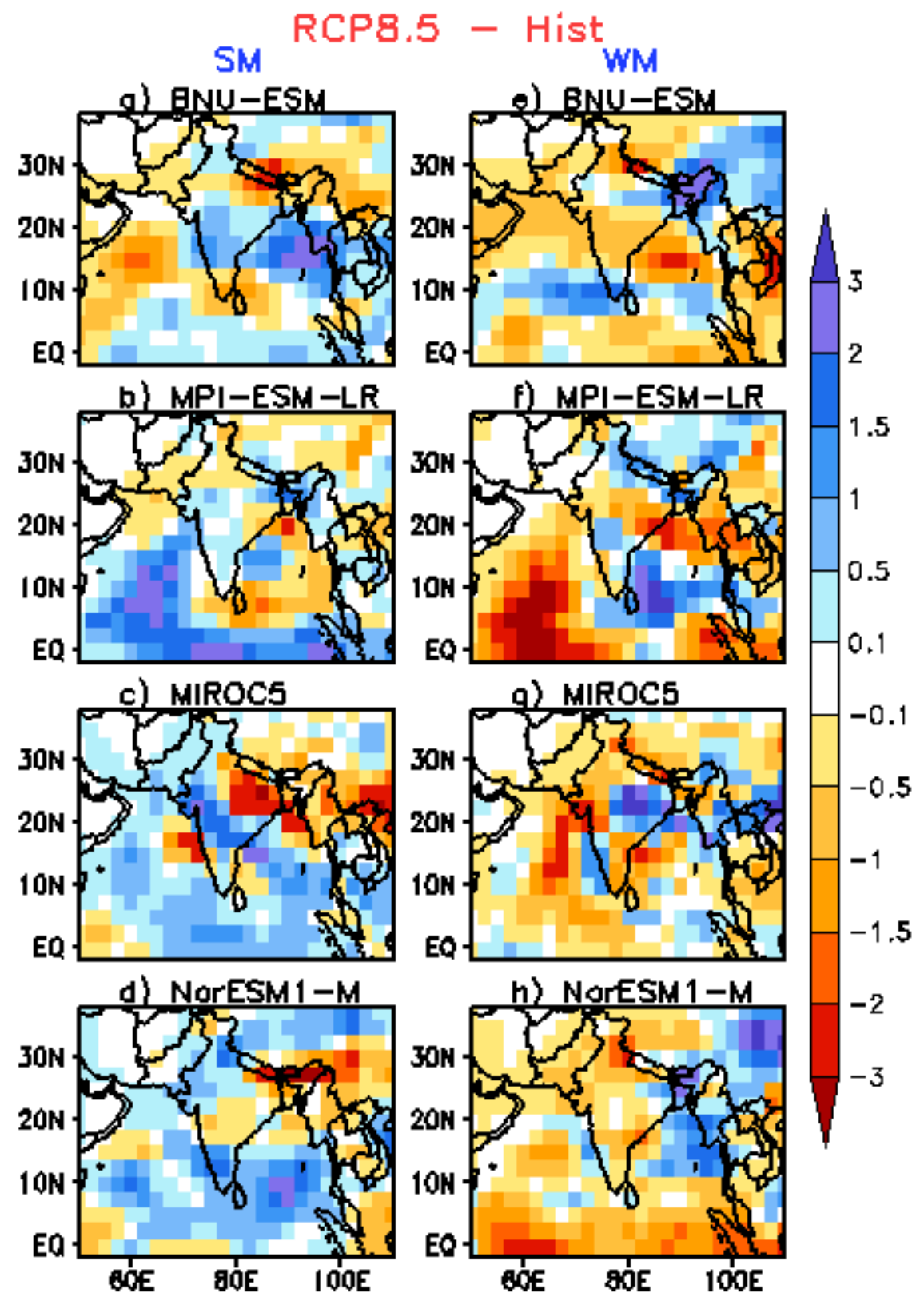

Figure 7 Projected changes (RCP8.5 - Hist) in seasonal mean rainfall (mm/day) during strong monsoon (SM: $a-d)$ and weak monsoon (WM: $e-h$ ) for selected models.

3.4 Future projection of intraseasonal variability and extreme events

\subsubsection{Changes in day-to-day variability}


A large amount of rainfall variability is related to the occurrence of extreme rainfall events and their intensities. Any change in the individual daily rainfall events can have a large impact on JJAS mean rainfall amount (Stephenson et al., 1999). Also understanding the changes in the spatial variability of extreme rainfall events will further help to identify the projected regions of extreme variability. Therefore, in this study, the probability distribution function (PDF) of daily rainfall at each grid over ISM domain during all JJAS periods is calculated for three rain-rate categories (lighter/low: $<10 \mathrm{~mm}$ day $^{-1}$, moderate: $10-40 \mathrm{~mm}$ day $^{-1}$ and high/heavy: $>40 \mathrm{~mm} \mathrm{day}{ }^{-1}$, following Mukhopadhyay et al. 2010) for all simulations.

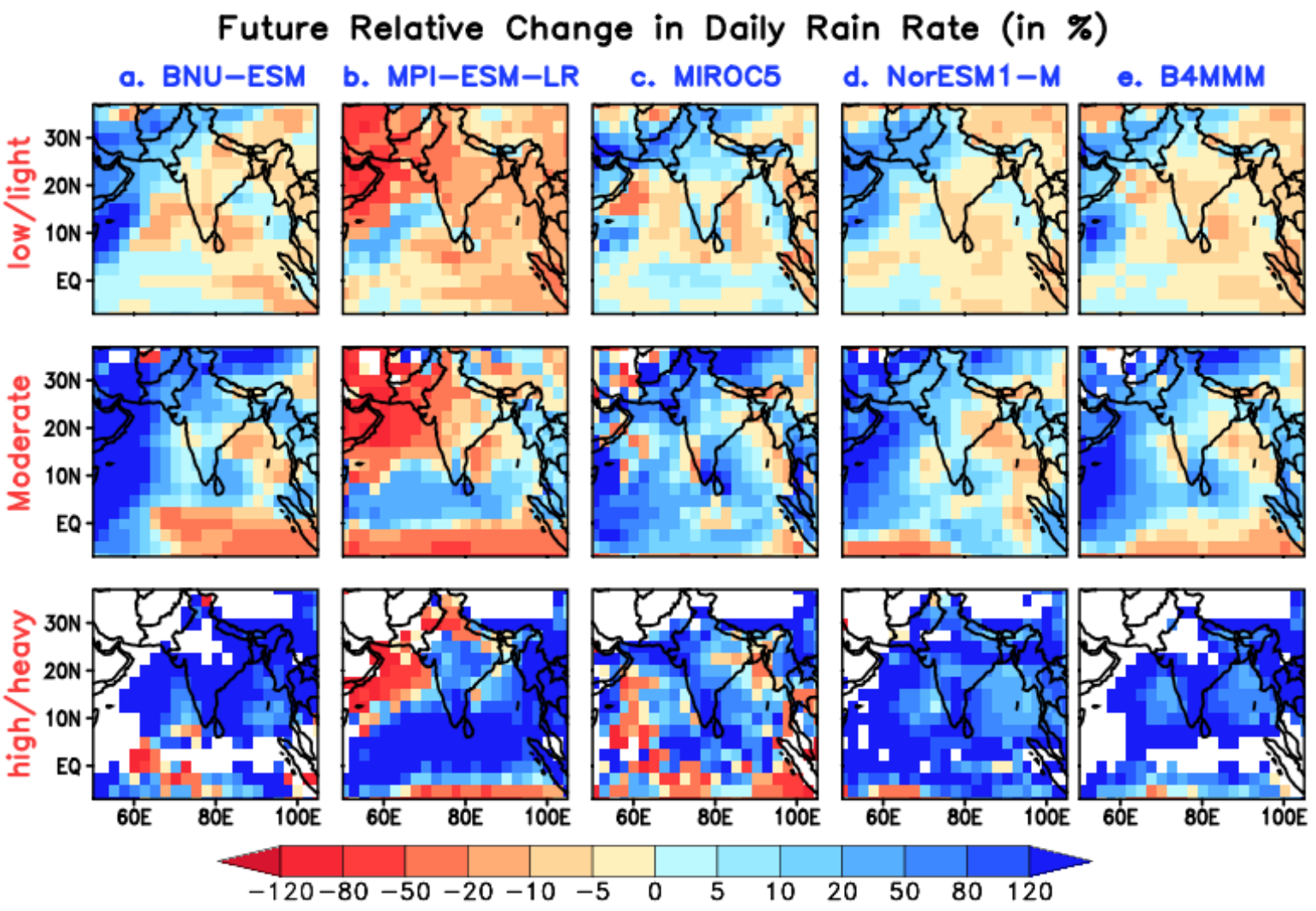

Figure 8 Relative changes (\%) in the daily rain-rate distribution (low <10mm/day; moderate $<10-40 \mathrm{~mm} /$ day $>$; and high $>40 \mathrm{~mm} /$ day) under $R C P 8.5$ scenario.

Figure 8 shows the projected spatial changes in the distribution of these three main rain-rate categories relative to present climate over ISM region for all models. It is noted that the projected substantial changes in the daily variability of ISM are largely associated 
with the increase in heavy rainfall events over Indian land and adjoining oceanic regions. Considerable decrease in the low rain-rate, even in moderate rain-rate (large change in MPIESM-LR) is also anticipated in future, indicating the rising climate-related vulnerability over Indian subcontinent as evident from B4MMM. Such projected increase in frequency and intensity of extreme rainfall events over ISM region in the backdrop of global warming may further decrease the potential predictability of ISM variability. Together with the notable increase in extreme events in response to climate change, it is anticipated that the number of wet days may also change through the monsoon season and may affect the JJAS rainfall intensity. Here, the wet days are defined when precipitation exceeds $0.1 \mathrm{~mm} /$ day on a given day whereas the rainfall intensity is defined as the ratio of total seasonal precipitation divided by number of wet days per season at each grid (following Turner and Slingo, 2009).

The possible spatial changes in wet days and relative change in precipitation intensity are shown in Figure 9. The figure illustrates that wet days over IND region might be reduced under climate change scenario; however there still exists uncertainty among the models (Figure 9a). Most models show relatively small increase in wet days over some part of equatorial Indian Ocean but considerable decrease to the south of the equator (except MIROC5). However, the response of precipitation intensity to increased GHG forcing is large (Figure 9b). Despite projecting a decrease in wet days, all models projected positive change in rainfall intensity over IND region particularly over western-central to peninsular Indian region, indicating the rise in heavy rainfall events. A large north-south asymmetry in relative change in rainfall intensity is indicated over ISM region with substantial decrease over EEIO in accordant with Fig. 3. 
a. Wetdays change
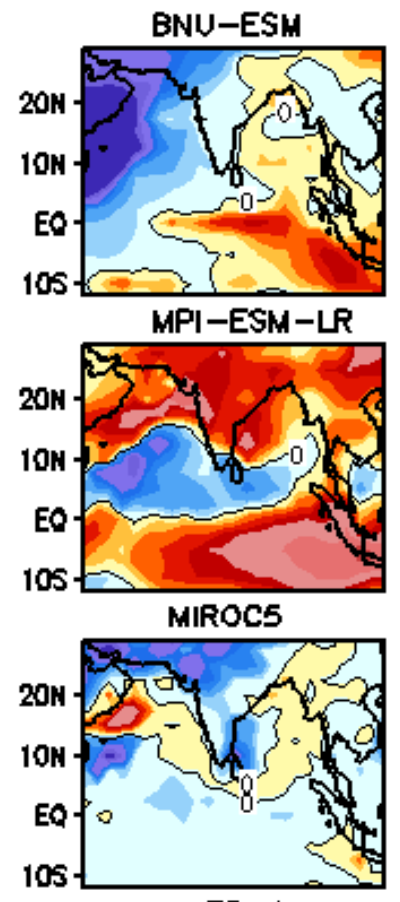

NorESH 1 -M

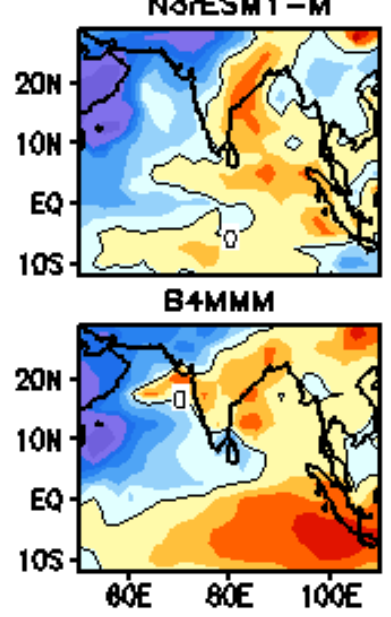

b. Precip intensity

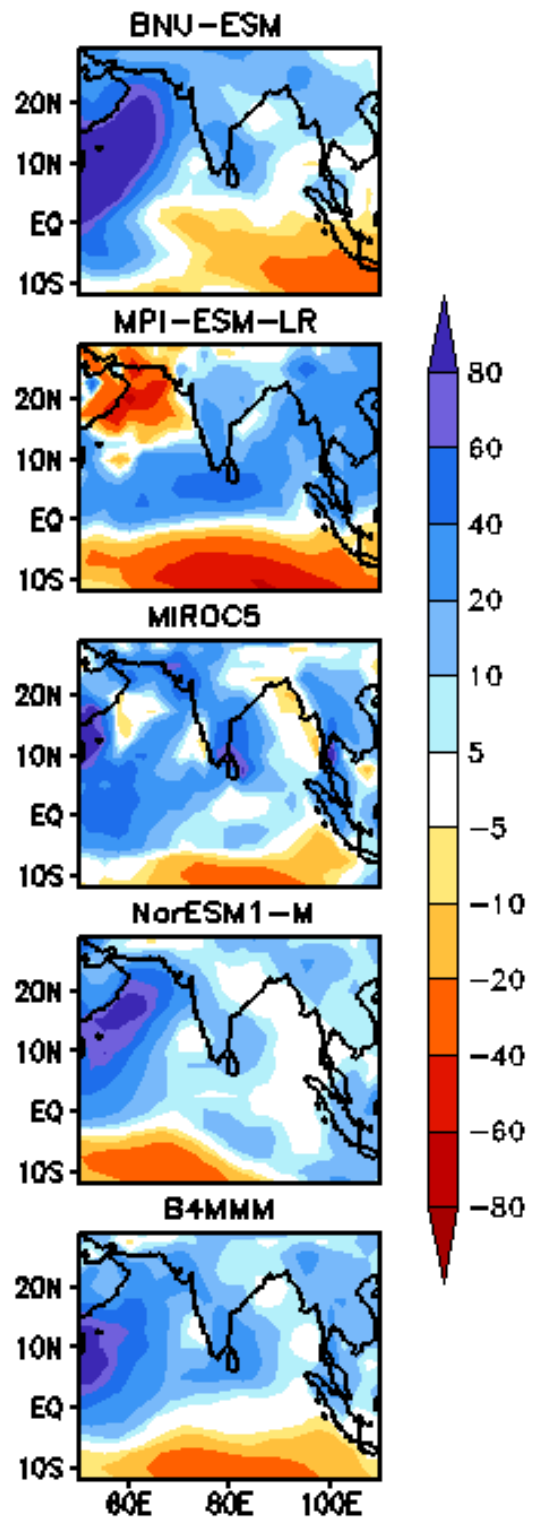

Figure $9 \boldsymbol{a}$. Projected changes in the number of wet days per season of ISM and $\boldsymbol{b}$. relative change in the summer mean rainfall intensity under $R C P 8.5$ scenario.

\subsubsection{Possible changes in ISV activity}

On the subseasonal timescale, the overall statistics of ISV activity is strongly interlaced with a large fraction of daily variability, synoptic activity and seasonal mean state of ISM. The impact of increased GHGs on future ISV remains uncertain and is one of the critical issues in monsoon climate-change research. In this subsection, we estimate the response of ISV activity in future climate from the best 4 models. 


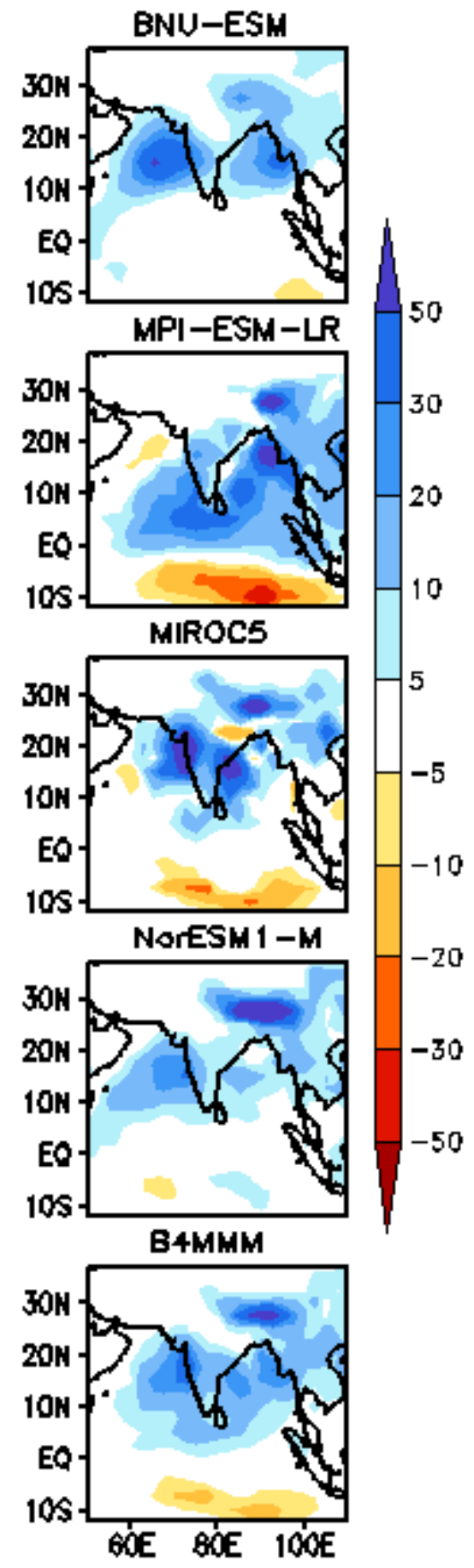

Figure 10 Projected future changes (\%) in the intraseasonal activity using 10-90 day band-pass filtered daily simulated rainfall under RCP8.5 scenario.

Figure 10 shows the projected changes in the spatial distribution of intraseasonal (10-90 day bandpass filtered) variance of daily precipitation under RCP8.5 scenario. Projections suggest that future ISV will enhance over IND region, particularly over northeastern and north-western part of Indian subcontinent. Large increase in variance is also projected over the adjoining oceanic regions; especially over EIO, Arabian Sea near Western 
Ghats, and head Bay of Bengal). It is noted that the projected change in the ISV activity is interlaced with the overall change in the seasonal rainfall intensity.

\subsubsection{Changes to propagation characteristics}

Within the 10-90 day mode of ISV activity, two dominant quasi-periodic intraseasonal timescales in the periods ranging from 10-20 day and 30-60 day causes intermittent wet/dry spells over ISM domain (Goswami 2011). To identify the future changes in spacetime characteristics of these modes, the meridional wavenumber frequency spectra of simulated daily precipitation is calculated over ISM domain $\left(15^{\circ} \mathrm{S}-30^{\circ} \mathrm{N} ; 65^{\circ}-95^{\circ} \mathrm{E}\right)$ during May to October from both the historical and corresponding climate change scenarios for all selected models. The model simulated spectrum of present climate shows a dominant northward propagating mode of 30-60 day period at wavenumber 1 with maximum power varying at $\sim 45-55$ days in consistently from all models (figures not shown). To estimate the relative change in the dominant modes, the meridional power spectrum are averaged over 1-2 wavenumbers for all the models (Figure 11) as the dominant 30-60 day mode of ISOs spans mostly within this range. The future change under RCP8.5 scenario shows relative enhancement ( 7-10\%) of power within higher frequency (15-30-day as well as below 10day mode). While the power increases in the higher frequency modes, it substantially decreases in lower frequency (beyond 45-day) for most of the models. These results indicate a possible periodicity shift (from lower to higher frequency) of the dominant ISV modes over ISM domain in future climate, although uncertainty still exists. It may be speculated that the increase in the high frequency ISOs may be connected with the projected extension of the westward propagating disturbances from the warmer Western Pacific into the ISM region (Figure 3). 


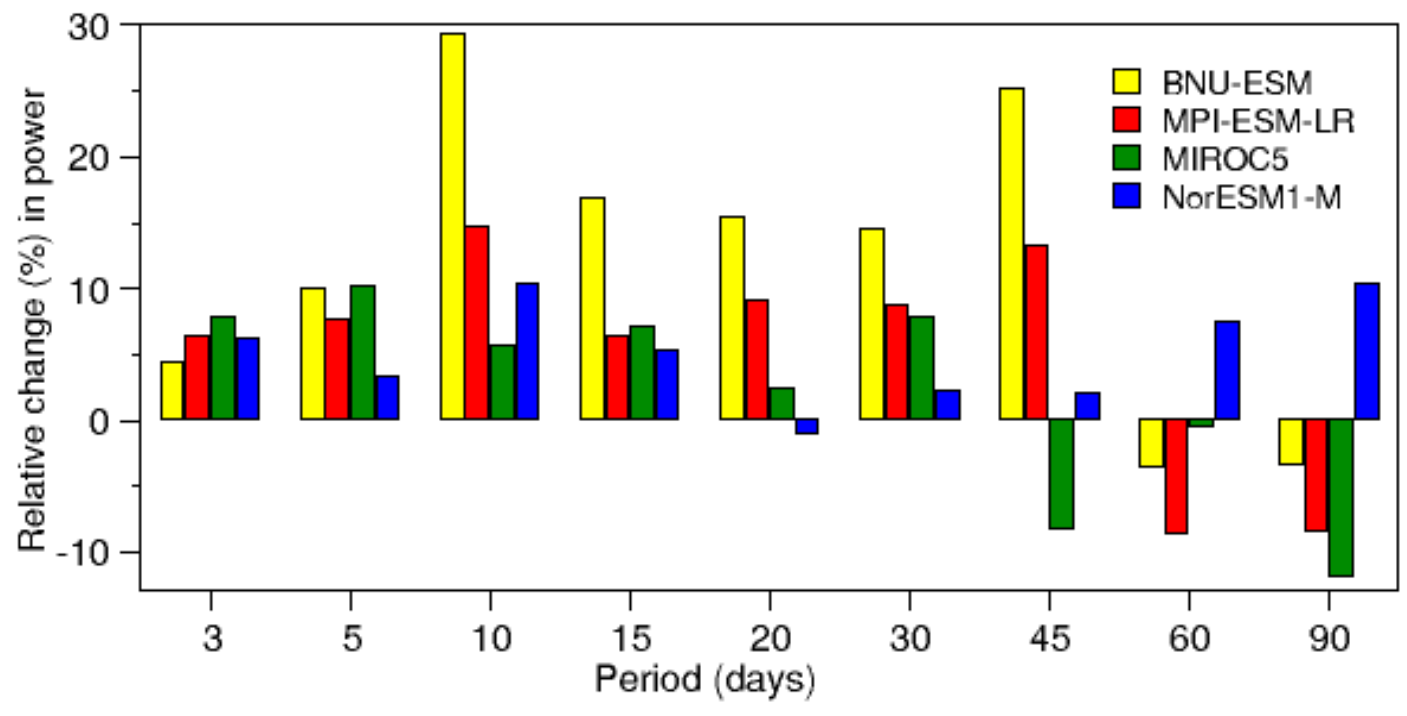

Figure 11 Projected relative changes (\%) in the meridional power spectra (northward component) of daily precipitation averaged over wavenumbers 1-2 during boreal summer over Indian domain $\left(15^{\circ} \mathrm{S}-30^{\circ} \mathrm{N} ; 60^{\circ} \mathrm{E}-95^{\circ} \mathrm{E}\right)$.

Now, it is worthwhile to estimate the change in the dominant northward propagating monsoon ISO under warming scenario. Figure 12 shows the time-latitude diagrams of lag-regressed 30-70 day band-pass filtered precipitation anomalies averaged over Indian longitude $\left(70^{\circ}-90^{\circ} \mathrm{E}\right)$ for present climate (left column) and RCP8.5 scenario (right column). The lag regression is performed based on first EEOF mode over ISM domain $\left(15^{\circ} \mathrm{S}-\right.$ $30^{\circ} \mathrm{N}$ and $65^{\circ}-95^{\circ} \mathrm{E}$ ) discussed in Sec. 2.3 . Here day 0 is considered as the day of rainfall maxima over core monsoon region. All models show prominent northward propagation of monsoon ISO from the equatorial region (around day -20) along with a realistic southward propagation in the historical simulation (Fig. 12 I). Under the increased GHGs induced climate change (Fig. 12 II), most of the models project intensified monsoon ISO around day 0 over monsoon core region. Subsequent enhanced suppression of convection over the equatorial region is also evident (largely in MPI-ESM-LR). Some models even project reduced southward propagating mode compared to present climate. It is noteworthy that the projected overall character of the dominant northward propagating low frequency monsoon 
ISOs (from EIO to Indian subcontinent) does not show remarkable change in a warmer climate, although the magnitude amplifies over ISM domain possibly due to moisture availability. Therefore, it may be suggested that along with the amplified 30-70 day mode, the enhanced high frequency mode and periodicity shift (from high to low) of monsoon ISOs due to increased GHG induced warming may notably modulate the monsoon rainfall over Indian subcontinent in a warmer climate.

I. Hist
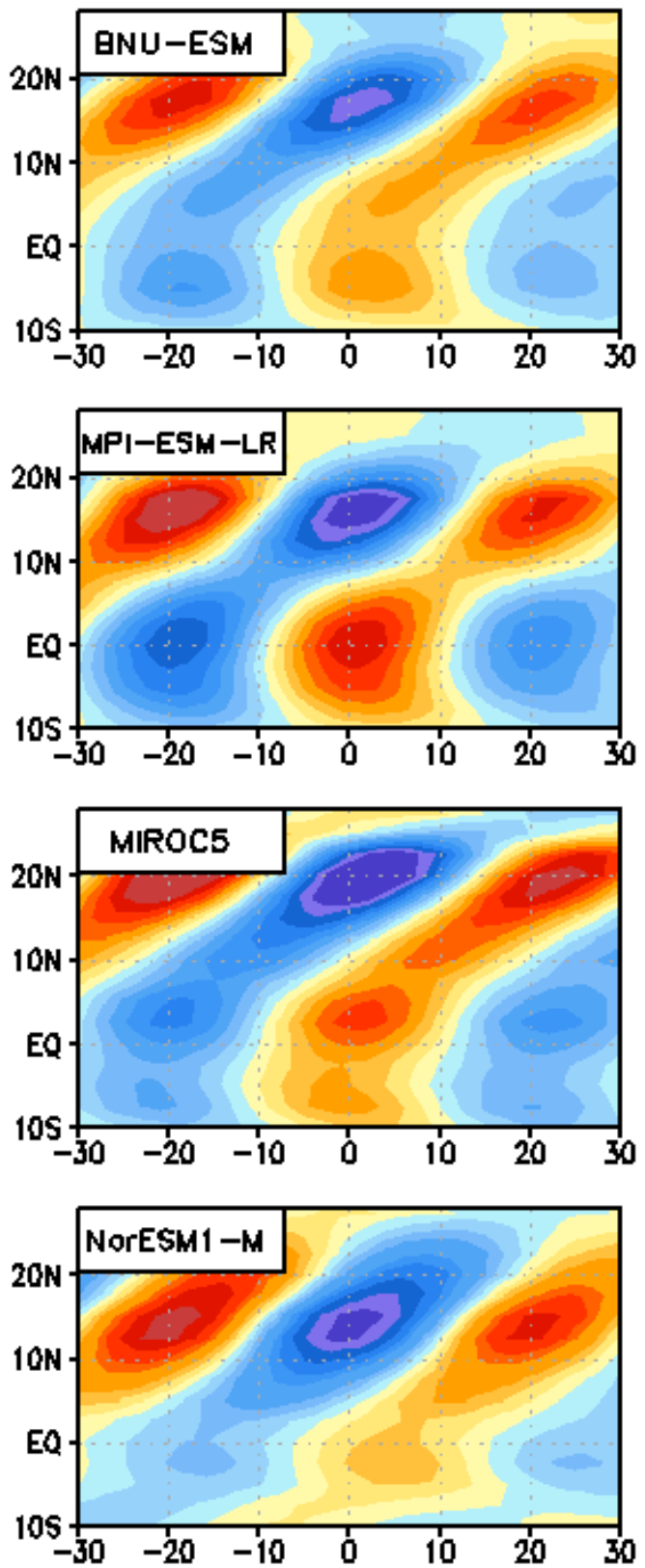

II. RCP8.5
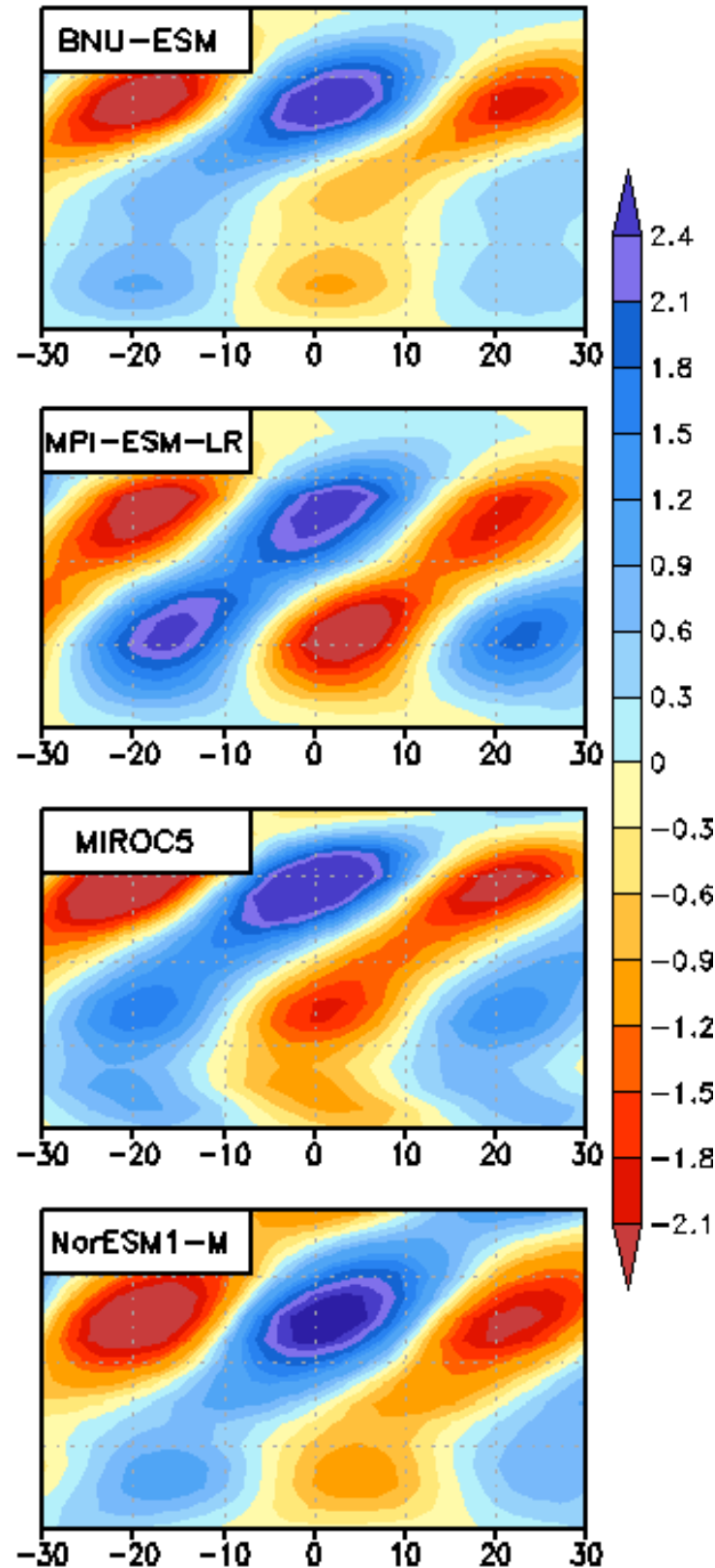

Figure 12 Time-latitude diagram of regressed 30-70 day filtered precipitation anomalies averaged over $70^{\circ} \mathrm{E}-90^{\circ} \mathrm{E}$ for historical run (left column) and following RCP8.5 scenario (right 
column) respectively. This corresponds to first EEOF mode of intraseasonally filtered precipitation over $15^{\circ} \mathrm{S}-30^{\circ} \mathrm{N}$ and $65^{\circ}-95^{\circ} \mathrm{E}$ domain during June to September.

\subsubsection{Future behaviour of active-break cycles}

It is expected that the considerable projected increase in the higher frequency mode (below 30 day) and amplification of 30-70day monsoon ISOs may influence the future change in the frequency and duration of these spells under enhanced GHG induced warming. To identify the possible change in the future behaviour of active-break spells, first all simulated active and break spells of the present climate and corresponding future emission scenario are identified using the method discussed in Sec. 2.3. The identified active/break spells are divided into two categories in terms of duration: (1) spells of 3-4 days as short spells, and (2) spells of duration $>=7$ days as long/extended spells. The frequency distributions of simulated active/break spells from historical runs are then compared with OBS, calculated from IMD daily rainfall for the same period (1951-1999). It is noted that the frequency distribution (in percentage) for active/break spells simulated from historical runs of all selected models are almost comparable with OBS (Figure 13a). This again affirms the reliability of the chosen models for studying ISV of ISM in this present study. The simulated present climate active/breaks during extreme monsoons also capture the observed asymmetry of duration, i.e; preference of long (short) active spells during SM (WM) and extended (short) breaks during WM (SM) (Sharmila et al. 2014) to some extent (figure not shown). Now to examine the possible change in $21^{\text {st }}$ century climate, the relative change in the spells under RCP8.5 scenario is shown in Figure $\mathbf{1 3 b}$. Most of the models project a relative increase of $\sim 5-15 \%$ in short active spells, even in the spells of 5-6 days (figure not shown), while $\sim 8-20 \%$ relative decrease in long active spells compared to present climate in response to increased GHG warming. For break spells, relative increase of $10-20 \%$ has been projected in both short and extended breaks with moderate consistency. 
a) Historical simulation of act-brk spells
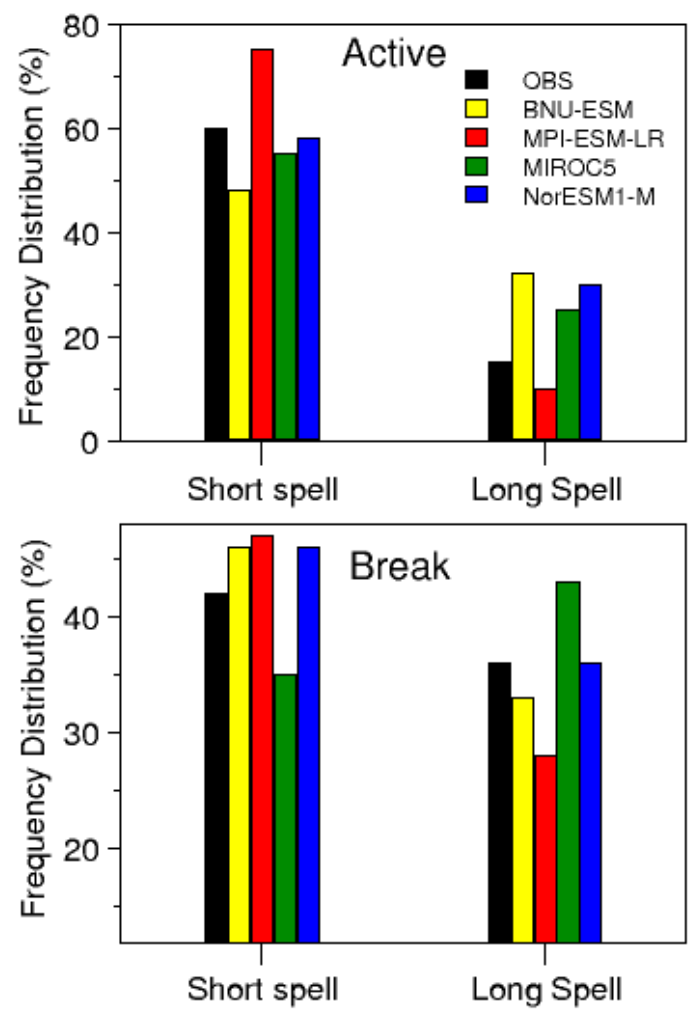

b) Projected changes to act/brk spells
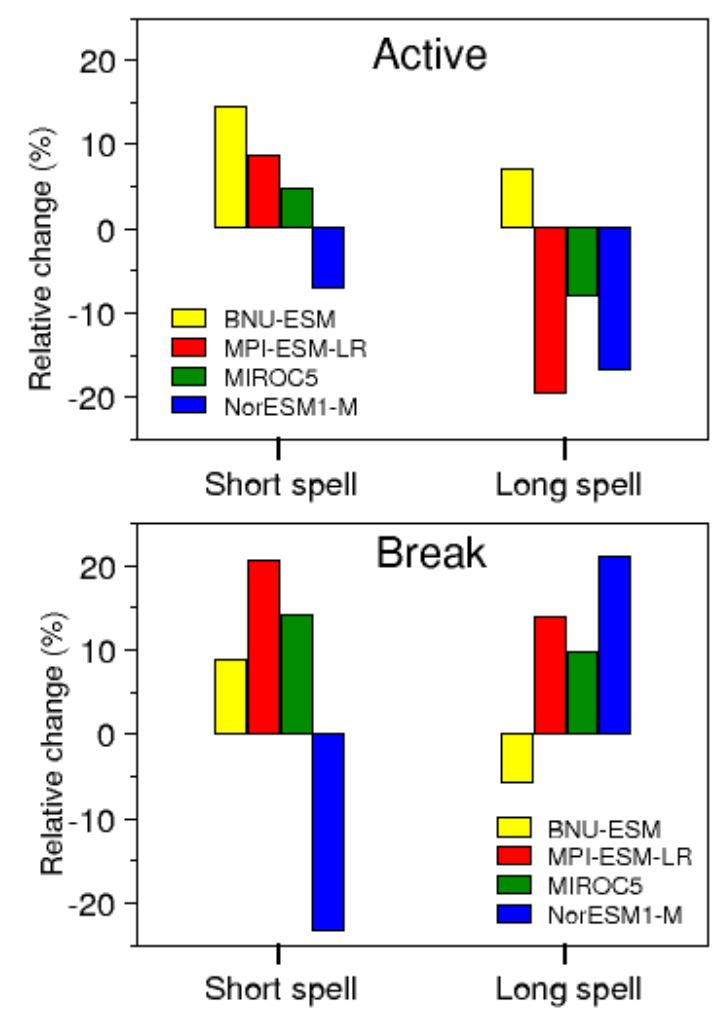

Figure 13 a. Frequency distribution (\%) of active/break spells divided into two categories in terms of duration: short (3-4 days) and long spells (>=7days) in historical runs compared to observation for the period of 1951-1999, and $\boldsymbol{b}$. Projected relative changes (\%) during 20512099 under RCP8.5 scenario.

Moreover, the relative changes in active/break spells during extreme monsoon years are also projected. Figure $\mathbf{1 4}$ shows that the longer active spells will be more frequent, while breaks will be fewer and shorter, leading to wetter SM in future. In contrast, WM will be drier due to the high propensity of extended breaks and short active spells in response to enhanced GHG, thereby increasing the risk of both the floods and drought like conditions over Indian subcontinent in future climate. 


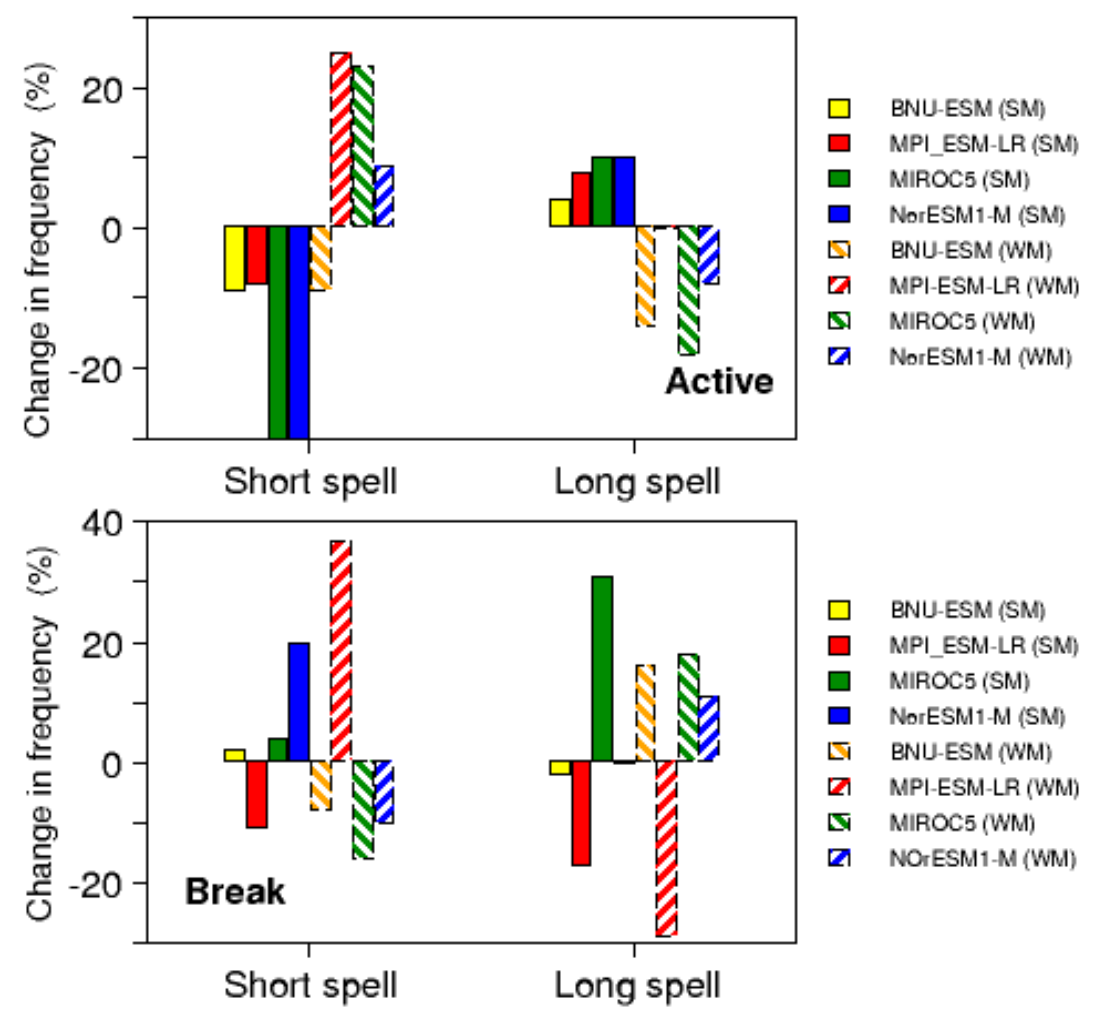

Figure 14 Projected changes (\%) in the frequency of active-break spells during strong monsoon (solid lined bar) and weak monsoon (dash lined bar) under climate change scenario.

Now, to assess the spatial changes in the active-break cycles under climate change scenario, active-break days are identified (discussed in Sec 2.3) and composites of active and break phases are constructed using 10-90 day filtered precipitation anomalies. Figure 15a-f shows the spatial composite of active spells from historical simulation compared to OBS $\left(1^{\text {st }}\right.$ column). It illustrates that the modelled patterns of present climate large scale organized positive precipitation anomalies around the core monsoon zone, the suppressed convection over EIO and the eastward tilted structure resemble well with GPCP (Fig. 15a). The corresponding changes in active composite under RCP8.5 scenario are shown in Figure 15g$\mathbf{k}\left(2^{\text {nd }}\right.$ column $)$. Consistent among the models, B4MMM projects regionally enhanced rainfall over core monsoon zone along with dominant east-west variation over ISM domain. Moreover, enhanced suppression of rainfall over Bay of Bengal is also projected. It is 
speculated that the projected enhancement of high frequency mode of monsoon ISOs may enhance regional character of the future active spells. In similar manner, the simulated break composites of present climate are shown and the prime features are well captured in the historical runs for all selected models ( $3^{\text {rd }}$ column; Fig. 15I-q). The projections show further suppression of rainfall around the core monsoon zone of Indian land during breaks under enhanced GHG-induced warming (last column; Fig. 15r-v). The robustness of these projected results across the selected models provide confidence in suggesting that the precipitation anomalies would become more intense and regionally extend over Indian land during active/break cycles in future climate. Such intensification of the active-break cycles may be caused by the overall intensification in the hydrological cycles due to significant change in the moisture content along with the substantial changes in the large scale circulation.

Similarly, the projected spatial changes in the precipitation anomalies during active/break phases of SM and WM are shown in Figure 16. The projected change in active composite during SM shows enhanced precipitation over core monsoon region (Fig 16 la-d) in future, while reduced rainfall is evident during active phase of WM (Fig 16 le-h) in most of the models (except MIROC5). Such changes are probably linked with the projected increase in the frequency of longer (shorter) active spells during SM (WM) in future as discussed earlier. Consistent results are also noted in projecting future spatial changes in break composites. Fig. 16.Il shows that the breaks might be weaker (stronger) during SM (WM), over core monsoon zone during WM consistent with Fig. 14. Therefore, it could be summarised that the present climate ISV during extreme monsoon will be more severe and intense in future climate. However, the projected changes are variable geographically and therefore uncertain among the selected models. 
a) GPCP

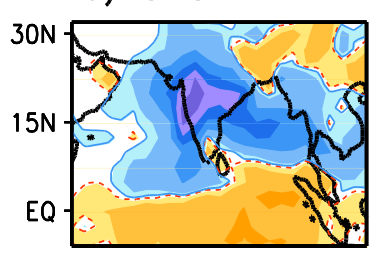

Hist

b) BNU-ESM

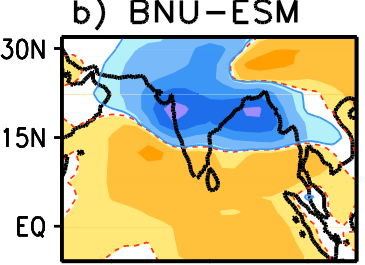

c) $M P I-E S M-L R$
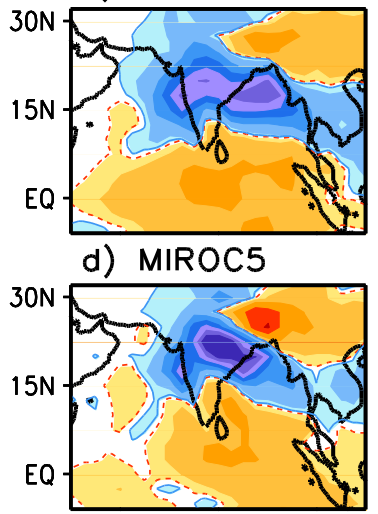

e) NorESM1-M
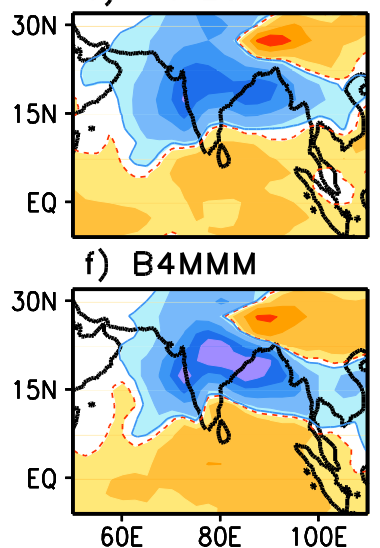

Active

Composite

RCP8.5-Hist
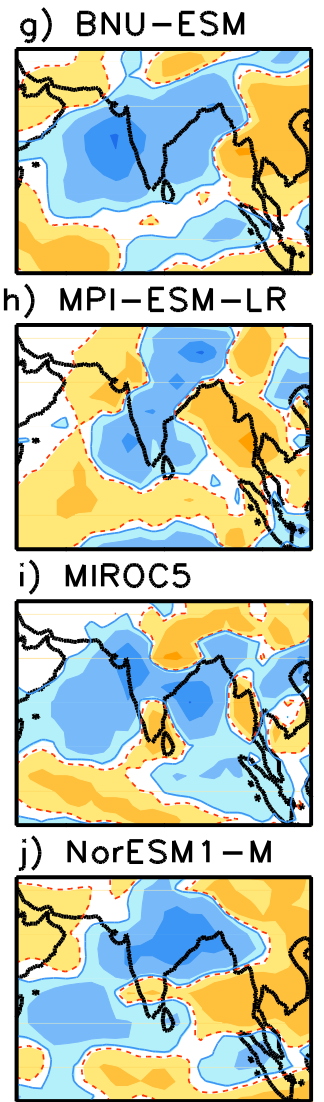

k) B4MMM

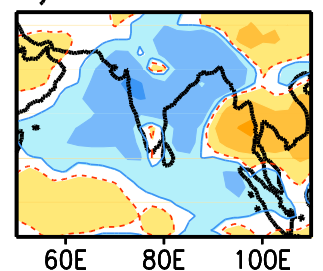

1) $\mathrm{GPCP}$

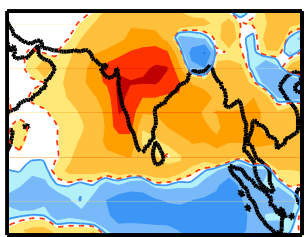

Hist

m) BNU-ESM

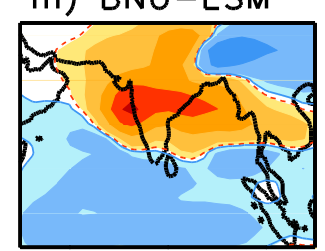

n) $M P I-E S M-L R$

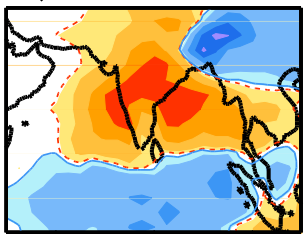

o) MIROC5

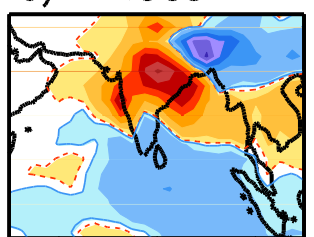

p) NorESM $1-M$

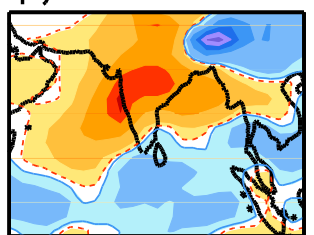

q) $84 \mathrm{MMM}$

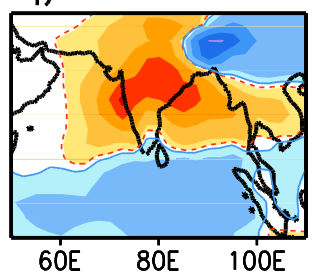

RCP 8.5-Hist

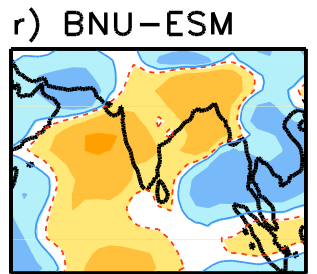

s) MPI-ESM-LR

Break

Composite
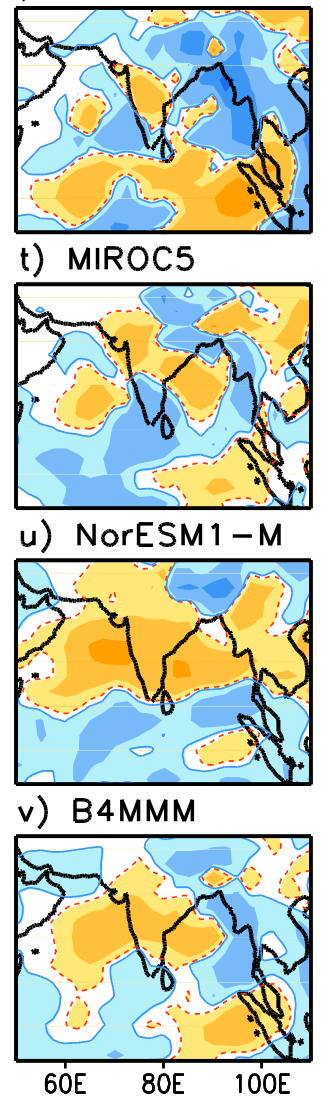

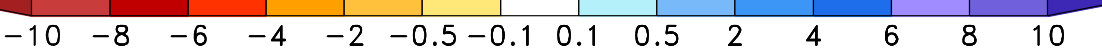

Figure 15 Active composite of 10-90 day filtered daily precipitation anomalies as simulated in the historical runs ( $a-f ; 1^{\text {st }}$ column) compared to OBS (GPCP) and corresponding change under RCP8.5 scenario ( $g-k ; 2^{\text {nd }}$ column). Similarly break composites are shown in $1-v$ for selected models and their MMM. 

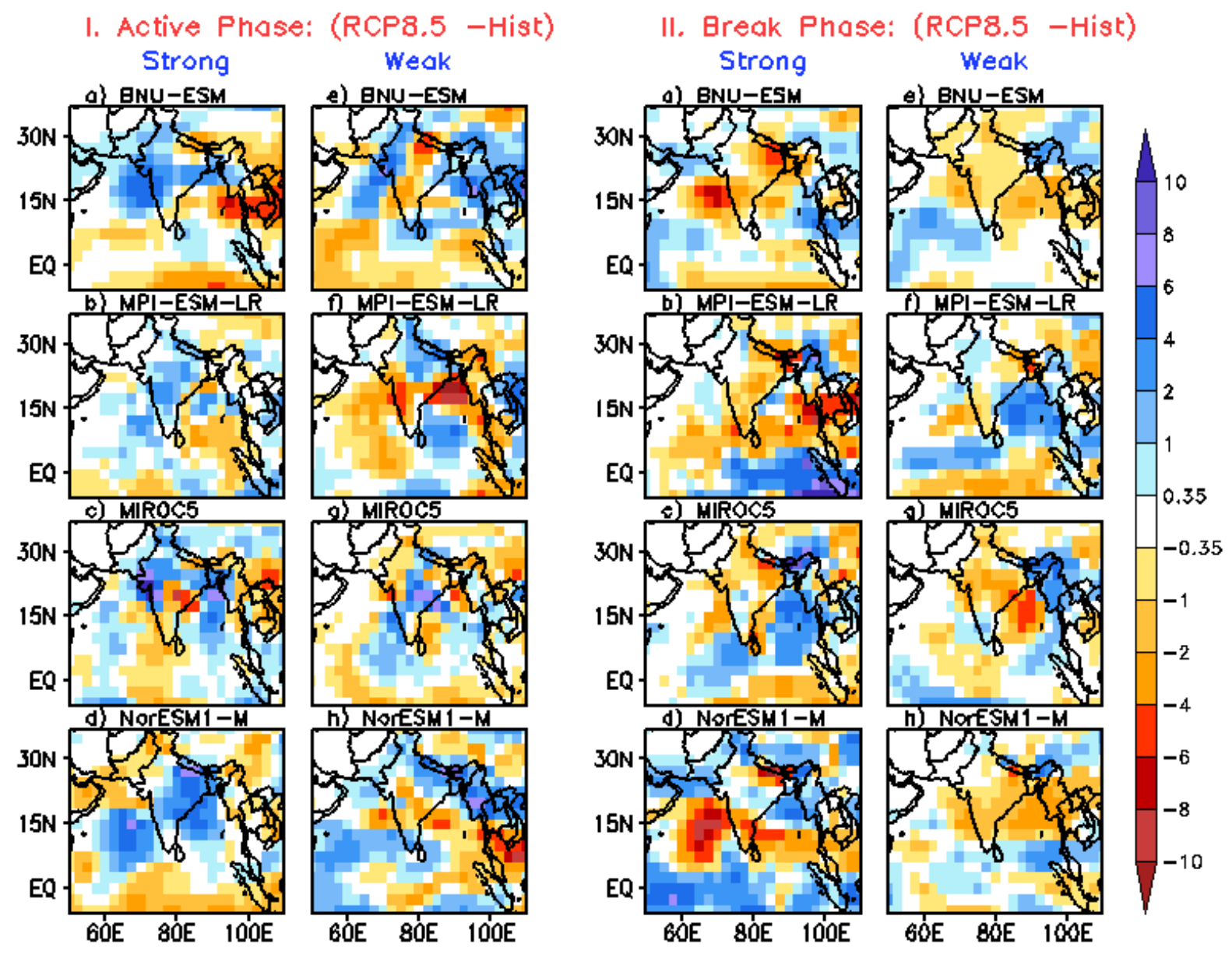

Figure 16 Projected changes (RCP8.5 -Hist) [(2051-2099) minus (1951-1999)] in the composited active (I.) and break (II.) phases using 10-90 day filtered daily precipitation anomalies during strong (I. a-d and II. a-d) and weak monsoon (I. e-h and II. e-h) years respectively.

\section{Concluding remarks}

The endurance of the growing populations and the developing socio-economic situations in India are predominantly interlaced with ISM variability. Thus, any change in monsoon rainfall due to enhanced GHG-induced climate change will have undeviating implications on water resources, agricultural output, public health and economy of the subcontinent. In this study, the potential future spatio-temporal changes in different aspects of ISM variability have been assessed using 20 state-of-the-art climate models from CMIP5 under RCP8.5 
climate change scenario. Optimal selection criteria have been used to identify most realistic and reliable climate models in simulating the basic features of ISM variability. Out of twenty models, only four models (viz. BNU-ESM, MPI-ESM-LR, MIROC5 and NorESM1-M) are able to reproduce some of the salient features of the ISM realistically. These models are then selected for further climate change analysis. The model results show that the response to climate change is plausibly consistent among the selected models, especially among the ESMs. Under the climate change scenario, the robustness of the projected results across the four better models and B4MMM provides confidence to suggest that the overall future change in ISMR is accompanied by the substantial changes in the variability on different time scales, ranging from daily to subseasonal to interannual variations during boreal summer beyond the mid $21^{\text {st }}$ century.

On seasonal-to-interannual timescales, the model projections indicate that the seasonal mean all-India summer monsoon rainfall and its IAV may noticeably increase in future climate. It may primarily be driven by the considerable increase in the thermodynamic conditions over ISM region due to GHG-induced warming, although slightly offset by weakening of the large scale monsoon circulation and the stabilization of atmosphere in warmer climate. It is expected that the rainfall magnitude might amplify over the core monsoon zone and length of the season may enhance due to late withdrawal, with no change in monsoon onset time. Further, model projections on IAV of ISM suggest that severity and frequency of both the SM and WM seasons may increase in future climate. However, projected change in the spatial patterns of seasonal rainfall during extreme monsoon is variable at regional scales with some uncertainty.

The PDF analysis of daily precipitation at each grid indicates that there could be significant enhancement in heavy rainfall events ( $>40 \mathrm{~mm} /$ day) over ISM domain along with reduced low rain-rate $(<10 \mathrm{~mm} /$ day $)$ events and decrease in number of wet days. However 
an increase in seasonal mean rainfall intensity is anticipated in future climate. On subseasonal scale, considerable changes in spatio-temporal scales of the ISV have been projected among the models with notable enhancement of 10-90 day ISV activity over Indian Ocean to the north of the equator. The meridional wavenumber frequency spectra of future daily precipitation over ISM domain indicate considerable amplification of higher frequency components of monsoon intraseasonal oscillations (ISOs) during boreal summer in response to enhanced GHG warming. However, the projected overall character of the dominant northward propagating 30-70 day mode monsoon ISOs does not show remarkable change in a warmer climate, although the magnitude amplifies over ISM domain possibly due to moisture availability. The models further project that the future active/break cycles might be more intense and regionally extended in future climate, with enhanced propensity of both short and long active/break spells. Moreover, the projection of ISV during extreme monsoon also indicate that SM might be wetter in future due to increase in longer active spells with decreasing break spells whereas WM would be drier with increase in very long breaks and shorter actives in future. These results indicate more severe drought and flood like conditions over Indian subcontinent in future climate. However, the projected changes in spatial structure of active/break during extreme monsoon years are geographically variable among the selected models.

It is worth to be noted that a small amount of uncertainty in projecting various aspects of ISM variability still exists among the selected models; e.g. the uncertainty in projecting ISV during extreme monsoons could be attributed to significant underestimations of ISMR-ENSO teleconnection and other physical processes by CMIP5 models (Jourdain et al. 2013). However, assessing the role of such changes is beyond the scope of this study. The internal variability of the climate models could also introduce some uncertainty in the model projection (Deser et al. 2012), which has been ignored in this study by considering 
only one ensemble of each model. The nature of such projections of ISM variability however, could also be complicated by the uncertain role of aerosols. The direct/indirect radiative effects of atmospheric aerosol loading represented in these CMIP5 models could add more uncertainty in the future estimation as they are considered to influence the present-climate monsoon variability in various ways (Manoj et al. 2011; Bollasina et al. 2011). Nevertheless, the consistent projections from the selected models in most of the aspects of ISM variability offer more confidence in the results and suggest the requisite of profound adaptation measures and better policy making in future.

\section{Acknowledgements}

This research work is a part of the Ph.D. thesis of S.S. financially supported by the Council for Science and Industrial Research (CSIR). The authors thank the Editor Dr. K. McGuffie, and the two anonymous reviewers for their insightful comments that helped to improve the earlier manuscript. World Climate Research Programme's Working Group on Coupled Modelling, which is responsible for CMIP, along with the climate modelling groups (listed in Table 1) are duly acknowledged. For CMIP the U.S. Department of Energy's Program for Climate Model Diagnosis and Intercomparison provides coordinating support and led development of software infrastructure in partnership with the Global Organization for Earth System Science Portals. S.S. also thanks S.P. Gharge for his assistance in data download. The figures are prepared using GrADS and XMGRACE. The Indian Institute of Tropical Meteorology (IITM) is fully supported by the Ministry of Earth Sciences, Govt. of India.

\section{References}


Annamalai H (2011) Modelling the monsoons in a changing climate. Planet Earth 2011 Global warming challenges and opportunities for policy and practice. Prof. Elias Carayannis (Ed.) ISBN: 978-953-307-733-8.

Annamalai H, Hafner J, Sooraj KP, Pillai P (2013) Global Warming Shifts The Monsoon Circulation, Drying South Asia. J Clim 26:2701-2718. doi: 10.1175/JCLI-D-12-00208.1

Ashfaq M, Shi Y, Tung W, et al. (2009) Suppression of south Asian summer monsoon precipitation in the 21st century. Geophys Res Lett 36:L01704. doi: $10.1029 / 2008 G L 036500$

Bhaskaran B, Mitchell JFB, Lavery JR, Lal M (1995) Climatic response of the Indian subcontinent to doubled $\mathrm{CO}_{2}$ concentrations. Int J Climatol 15:873-892. doi: 10.1002/joc.3370150804

Bollasina MA, Ming M, Ramaswamy V (2011) Antrhopogenic aerosolsand the weakening of the South Asian summer monsoon. Science 334:502-505.

Cai W, Borlace S, Lengaigne et al. (2014) Increasing frequency of extreme El Niño events due to greenhouse warming. Nature Clim Change. DOI: 10.1038/NCLIMATE2100

Cherchi A, Alessandri A, Masina S, Navarra A (2011) Effects of increased $\mathrm{CO}_{2}$ levels on monsoon. Clim Dyn 37:83-101. doi:10.1007/s00382-010-0801-7

Dairaku K, Emori S (2006) Dynamic and thermodynamic influences on intensified daily rainfall during the Asian summer monsoon under doubled atmospheric $\mathrm{CO}_{2}$ conditions. Geophys Res Lett 33:L01704. doi: 10.1029/2005GL024754

Dash SK, Kulkarni M a., Mohanty UC, Prasad K (2009) Changes in the characteristics of rain events in India. J Geophys Res 114:D10109. doi: 10.1029/2008JD010572

Deser C, Phillip A, Bourdette V, Teng H (2012) Uncertainty in climate change projections: the role of internal variability. Clim Dyn 38:527-546. DOI 10.1007/s00382-010-0977-x

Duchon CE (1979) Lanczos Filtering in One and Two Dimensions. J Appl Meteor 18:10161022. 
Gadgil S, Rupa Kumar K (2006) The Asian monsoon-agriculture and economy. In Wang B (ed) The Asian monsoon. Springer, Berlin, pp 651-683.

Ghosh S, Das D, Kao SC, Ganguly AR (2012) Lack of uniform trends but increasing spatial variability in observed Indian rainfall extremes. Nature Clim Change 2:86-91. doi:10.1038/NCLIMATE1327

Goswami BN, Krishnamurthy V, Annamalai H (1999) A broad-scale circulation index for the interannual variability of the Indian summer monsoon. Quarterly Journal of Royal Meteorological Society 125: 611-633. DOI: 10.1002/qj.49712555412

Goswami BN, Venugopal V, Sengupta D, et al. (2006) Increasing trend of extreme rain events over India in a warming environment. Science (80- ) 314:1442-1445.

Goswami BN (2011) South Asian summer monsoon. In: Lau WK-M, Waliser DE (eds) Intraseasonal variability of the atmosphere-Ocean climate system, 2nd edn. Springer, Berlin, pp 21-72

Guhathakurta P, Rajeevan M (2008) Trends in the rainfall pattern over India. Int J Climatol 28:1453-1469. doi: 10.1002/joc

Hsu PC, Li T, Luo JJ, Murakami H, Kitoh A, Zhao M (2012) Increase of global monsoon area and precipitation under global warming: a robust signal? Geophys Res Lett 39:L0670. doi:10.1029/2012GL051037

Hu Z, Latif M, E R, Bengtsson L (2000) Intensified Asian summer monsoon and its variability in a coupled model forced by increasing greenhouse gas concentrations. Geophys Res Lett 27:2681-2684.

Huffman GJ, Adler RF, Bolvin DT, Gu G (2009) Improving the global precipitation record: GPCP version 2.1. Geophys Res Lett 36:L17808. doi:10.1029/2009GL040000

IPCC (2007) Climate change 2007- The physical science basis contribution of working group I to the fourth assessment report of the IPCC (ISBN 9780521 88009-I Hardback; 978 0521 70596-7 paperback) 
Joseph S, Sahai AK, Goswami BN, Terray P, Masson S, Luo JJ (2012) Possible role of warm SST bias in the simulation of boreal summer monsoon in SINTEX-F2 coupled model. Clim Dyn 38:1561-1576. doi:10.1007/s00382-011-1264-1

Jourdain NC, Sen Gupta A, Taschetto et al (2013) The Indo-Australian monsoon and its relationship to ENSO and IOD in reanalysis data and the CMIP3/CMIP5 simulations. Clim Dyn 41(11-12): 3073-3102. doi: 10.1007/s00382-013-1676-1

Kalnay E et al (1996) The NCEP/NCAR 40- year reanalysis project. Bull Am Meteorol Soc 77:437-471

Kitoh A, Yukimoto S, Noda A, Motoi T (1997) Simulated changes in the Asian summer monsoon at times of increased atmospheric CO2. J Meteorol Soc Japan 75(6):10191031.

Kitoh A, Endo H, Krishna Kumar K, et al. (2013) Monsoons in a changing world: A regional perspective in a global context. J Geophys Res Atmos 118:3053-3065. doi: 10.1002/jgrd.50258

Kripalani RH, Kulkarni A, Sabade SS (2003) Indian Monsoon Variability in a Global Warming Scenario. Nat Hazards 29:189-206.

Krishna Kumar K, Patwardhan SK, Kulkarni A, Kamala K, Rao KK, Jones R (2011) Simulated projections for summer monsoon climate over India by a high-resolution regional climate model (PRECIS). Curr Science, 101 (3):312-326. ISSN 0011-3891

Krishnan R, Sabin TP, Ayantika DC, et al. (2013) Will the South Asian monsoon overturning circulation stabilize any further? Clim Dyn 40:187-211.

Lal M, Nozawa T, Emori S, et al. (2001) Future Climate change: Implications for Indian summer monsoon and its variability. Curr Sci 81:1196-1207.

Lau WKM, Wu HT, Kim KM (2013) A canonical response of precipitation characteristics to global warming from CMIP5 models. Geophys Res Lett 40:3163-3169. doi: $10.1002 / \mathrm{grl} .50420$ 
Lee J-Y, Wang B (2014) Future change of global monsoons in the CMIP5. Clim Dyn 42: 101119. doi: $10.1007 / \mathrm{s} 00382-012-1564-0$

Mandke SK, Sahai AK, Shinde MA, Joseph S, Chattopadhyay R (2007) Simulated changes in active/break spells during the Indian summer monsoon due to enhanced $\mathrm{CO}_{2}$ concentrations : assessment from selected coupled atmosphere - ocean global climate models. Int J Climatol 27:837-859.

Manoj MG, Devara PCS, Safai PD, Goswami BN (2011) Absorbing aerosols facilitate transition of Indian monsoon breaks to active spells. Clim Dyn 37:2181-2198, doi:10.1007/s00382-010-0971-3.

May W (2004) Variability and extremes of daily rainfall during the Indian summer monsoon in the period 1901-1989. Glob Planet Change 44:83-105. doi: 10.1016/j.gloplacha.2004.06.007

May W (2011) The sensitivity of the Indian summer monsoon to a global warming of $2{ }^{\circ} \mathrm{C}$ with respect to pre-industrial times, Clim Dyn 37(9):1843-1868.

Meehl GA, Wahsington WM (1993) South Asian Summer Monsoon Variability in a Model with Doubled Atmospheric Carbon Dioxide Concentration. Science 260(5111):11011104. DOI: $10.1126 /$ science.260.5111.1101

Meehl GA, Covey C, Delworth T, Latif M et al (2007) The WCRP CMIP3 multi-model dataset: a new era in climate change research. Bull Am Meteor Soc 88:1383-1394

Mukhopadhyay P, Taraphdar S, Goswami BN, Krishna Kumar K (2010) Indian summer monsoon precipitation climatology in a high resolution regional climate model: Impact of convective parameterization on systematic biases. Weather and Forecasting 25:369387. doi:10.1175/2009WAF2222320.1

Pillai PA, Annamalai H (2012) Moist dynamics of severe monsoons over south Asia: Role of the tropical SST. Journal of Atmospheric Science 69:97-115. doi: http://dx.doi.org/10.1175/JAS-D-11-056.1 
Rajeevan M, Pai DS, Kumar AR, Lal B (2006) New statistical models for long-range forecasting of southwest monsoon rainfall over India. Clim Dyn 28:813-828. doi: $10.1007 / \mathrm{s} 00382-006-0197-6$

Rajeevan M, Bhate J, Jaswal AK (2008) Analysis of variability and trends of extreme rainfall events over India using 104 years of gridded daily rainfall data. Geophys Res Lett 35:L18707. doi: 10.1029/2008GL035143

Rajeevan M, Gadgil S, Bhate J (2010) Active and break spells of the Indian summer monsoon.J Earth Syst Sci 119:229-247.

Rao KK, Patwardhan SK, Kulkarni A, et al. (2013) Projected changes in mean and extreme precipitation indices over India using PRECIS. Glob Planet Change 113:77-90. doi: 10.1016/j.gloplacha.2013.12.006

Rupa Kumar K, Sahai AK, Kumar KK, Patwardhan SK, Mishra PK, Revadekar JV, Kamala K, Pant GB (2006) High resolution climate changes scenarios for India for the $21^{\text {st }}$ century. Curr Sci 90:334-345.

Sabeerali CT, Dandi AR, Dhakate A, Salunke K, Mahapatra S, Rao SA (2013) Simulation of boreal summer intraseasonal oscillations in the latest CMIP5 coupled GCMs. J Geophys Res 118:4401-4420. DOI: 10.1002/jgrd.50403

Sharmila S, Joseph S, Chattopadhyay R, Sahai AK, and Goswami BN (2014) Asymmetry in space-time characteristics of Indian summer monsoon intraseasonal oscillations during extreme years - Role of seasonal mean state. International Journal of Climatology, DOI:10.1002/joc. 4100

Singh D, Tsiang M, Rajaratnam B, Diffenbaugh NS (2014) Observed changes in extreme wet and dry spells during the South Asian summer monsoon season. Nature Clim Change, doi:10.1038/NCLIMATE2208

Sperber KR, Annamalai H, Kang I-S, et al. (2012) The Asian summer monsoon: an intercomparison of CMIP5 vs. CMIP3 simulations of the late 20th century. Clim Dyn 41:2711-2744. doi: 10.1007/s00382-012-1607-6 
Stephenson DB, Rupa Kumar K, Doblas-Reyes FJ, Royer JF, Chauvin F, Pezzulli S (1999) Extreme Daily Rainfall Events and Their Impact on Ensemble Forecasts of the Indian Monsoon. Mon Wea Rev, 127, 1954-1966.

Stowasser M, Annamalai H, Hafner J (2009) Response of the South Asian Summer Monsoon to Global Warming : Mean and Synoptic Systems. J Clim 22:1014-1036.

Tanaka HL, Ishizaki N, Nohara D (2005) Intercomparison of the intensities and trends of Hadley, Walker, and Monsoon circulations in the global warming projects. SOLA 1:077080

Taylor KE (2001) Summarizing multiple aspects of model performance in a single diagram. J Geophys Res 106(D7):7183-7192.

Taylor KE, Stouffer RJ, Meehl G A (2012) An Overview of CMIP5 and the Experiment Design. Bull Am Meteorol Soc 93:485-498. doi: 10.1175/BAMS-D-11-00094.1

Turner AG, Inness PM, Slingo JM (2007) The effect of doubled $\mathrm{CO}_{2}$ and model basic state biases on the monsoon-ENSO system . I : Mean response and interannual variability. Q J Royel Meteorol Soc 133:1143-1157. doi: 10.1002/qj

Turner AG, Slingo JM (2009) Subseasonal extremes of precipitation and active-break cycles of the Indian summer monsoon in a climate-change scenario. Q J Royel Meteorol Soc 567:549-567. doi: 10.1002/qj

Turner AG (2011) Modelling monsoons : Understanding and predicting current and future behaviour. In: Chang C, Ding Y, Lau N, et al. (eds) Glob. Monsoon Syst. Res. Forecast, 2nd Edition. World Scientific; WMO, pp 421-454

Turner AG, Annamalai H (2012) Climate change and the south Asian summer monsoon. Nature Clim Change 2:587-595

Ueda H, Iwai A, Kuwako K, Hori ME (2006) Impact of anthropogenic forcing on the Asian summer monsoon as simulated by eight GCMs. Geophys Res Lett 33:L06703. doi:10.1029/2005GL025336. 
Wang B, Fan Z (1999) Choice of south Asian summer monsoon indices. Bulletin of America Meteorological Society 80: 629-638.

Wang B, Yim S-Y, Lee J-Y, Liu J, Ha K-J (2014) Future change of Asian-Australian monsoon under RCP 4.5anthropogenic warming scenario. Clim Dyn 42:83-100. doi:10.1007/s00382-013-1769-x

Webster PJ, Yang S (1992) Monsoon and ENSO: Selectively interactive systems. Q J R Meteorol Soc 118:877-926. doi:10.1002/qj.49711850705.

Wheeler M, Kiladis GM (1999) Convectively coupled equatorial waves: Analysis of clouds and temperature in the wavenumber-frequency domain. J Atmos Sci , 56:374-399. 